\title{
Does persistence in idiosyncratic risk proxy return-reversals?
}

\author{
Harmindar B. Nath ${ }^{1}$ \\ Department of Econometrics and Business Statistics, \\ Monash University, Caulfield East 3145, Australia \\ mindi.nath@monash.edu \\ Vasilis Sarafidis \\ Department of Econometrics and Business Statistics, \\ Monash University, Caulfield East 3145, Australia \\ vasilis.sarafidis@monash.edu
}

\begin{abstract}
Understanding the return-reversal phenomenon observed to generate large abnormal profits under some stock market trading strategies is of considerable interest in finance. There is also much debate over the use of idiosyncratic risk as a predictor in asset pricing models when it is persistent. This paper, using the Australian data, presents new empirical evidence of return-reversals at the firm level and the existence of an equilibrium state based on robust econometric methodology of panel error-correction model. The method exploits the persistence in idiosyncratic risk and builds on its cointegration with the returns series. Our results reveal the tendency of long-run returns to restore equilibrium, reversals in short-run returns, a slower recovery to equilibrium by small stocks, and while the short-run responses of returns to changes in log book-to-market ratios are positive, their reaction to persistence in idiosyncratic volatility causes the reversal process. The pattern in quantile dependent coefficients of short-run idiosyncratic risk-return relationship suggests that (i) the changes in idiosyncratic volatility risk adversely affects the short-run returns of low performing stocks but investments in high performing stocks benefit from such changes; (ii) the increasing trend in the coefficients implies a quadratic relationship in the levels of the two series. The significant marginal effects of changes in idiosyncratic volatility and its one period lagged values on changes in returns at many quantiles support the impact being due to persistence in idiosyncratic risk, and their reversing signs provide an evidence of reversion in short-run returns.
\end{abstract}

JEL classification: C21; C23; C33; C58; G12

Keywords: Return reversals, idiosyncratic risk, panel cointegration, panel ECM, quantile regression

Corresponding author: Department of Econometrics and Business Statistics, Monash University, Caulfield East 3145, Australia, Tel: +61 39903 4345; Fax: +61 39903 2007, Email addresses: mindi.nath@monash.edu 


\section{INTRODUCTION}

The phenomenon of return-reversals observed to generate large abnormal returns under some stock-market trading strategies has attracted much attention in empirical finance. Understanding its generating process can help investors develop trading strategies for harvesting sizable returns. In this paper, utilising the Australian data, we present a new explanation of the incidence of short-run return-reversals at the firm level and the existence of an equilibrium state via empirical evidence based on robust econometric methodology of panel error-correction model (ECM) - a methodology that has not been applied or considered in past studies. The model exploits the persistence in idiosyncratic volatility risk and other explanatory variables, and builds on their cointegration with the returns series. It allows for the existence of an underlying long-run relationship between the returns and the explanatory variables, incorporates short-run adjustments in variables to correct persistence imbalance due to the nonstationary predictors within the panel data structure.

This paper links to two strands of literature: (i) 'devoted to understanding the return-reversal phenomenon (e.g., Avramov et al. 2006, Campbell, Grossman and Wang (henceforth CGW) 1993; Chordia et al. 2005; Jegadeesh 1990; Jegadeesh and Titman 1993; Lehmann 1990)'; (ii) 'related to asset pricing where the interest is to explore the behaviour of idiosyncratic volatility risk in explaining future stock returns (e.g., Ang et al. 2006, 2009; Fu 2009; Levy 1978; Malkiel and Xu 2004; Merton 1987)'. While Jegadeesh (1990) and Lehmann (1990) observe the return-reversal phenomenon from employing the contrarian trading strategy (buying past losers and selling past winners), Jegadeesh and Titman (1993) find its presence - the momentum reversals, when applying the relative strength or the momentum trading strategy (buy past winners and sell past losers). CGW (1993) explain this phenomenon via the rational equilibrium paradigm. In the asset pricing literature, the theoretical work of Levy (1978) shows that idiosyncratic risk affects equilibrium asset prices if investors do not hold a fully diversified portfolio of assets. The theory of Merton (1987) infers a positive relation between idiosyncratic risk and expected returns in under-diversified portfolios. Fu (2009), and Malkiel and Xu (2004) present empirical evidence to suggest that higher idiosyncratic risk produces higher expected returns in the cross section. However, the empirical studies of Ang et al. $(2006,2009)$ reporting a negative relationship in predictive models built on daily data over monthly frequencies have caused much debate over the form of the relationship. Fu (2009) and Huang et al. (2010) attribute the negative relationship observed in Ang et al. $(2006,2009)$ to return-reversals in stocks that have high idiosyncratic volatilities.

Following on the remarks of Jegadeesh and Titman (1993), who utilising the momentum strategy report observing initially positive and later negative returns, that the returns may have links to delayed price reactions to firm-specific information, we examine the return-reversal process by employing idiosyncratic volatility risk, book-to-market ratios and market capitalization of stocks as the firm-specific information factors, as opposed to liquidity and/ or volume used in earlier studies. Observing persistence in idiosyncratic volatility series is not uncommon. For the US data, Ang et al. (2009) and Jiang and Lee (2006) report idiosyncratic volatility series to be persistent over time, while Hur (2010) and Nath and Brooks (2015) observe persistence in idiosyncratic risk series based on the Australian data. There is much debate (e.g., Campbell and Yogo 2006; Jiang and Lee 2006) over the use of idiosyncratic risk as a predictor in asset pricing models when it is persistent.

The investigation in this paper finds the idiosyncratic volatility series possessing a unit root. We apply the ADF (Augmented Dickey Fuller) and the KPSS (Kwiatkowski, Phillips, Schmidt and Shin) tests for checking various time series for unit roots (i.e., random walks). Both tests reveal that the time series of idiosyncratic volatility risk, Insize (log of market capitalization) and $\mathrm{lnbm}$ (log of book-to-market) for the majority of the stocks considered follow nonstationary I(1) 
(i.e., integration of order one) processes, but the proportion of realized future excess returns series following an $I(1)$ process is small. The application of error-correction panel cointegration tests of Westerlund (2007) confirms panel cointegration between the time series of expected excess returns and the time series of idiosyncratic volatility $(\mathrm{IVol})$ and $\ln b m$, and allows the use of a panel ECM. This panel ECM involves all stationary variables and can be estimated using any of the classical estimation methods. We make use of the ordinary least squares (OLS) estimation for bench marking and the quantile regression method for obtaining a detailed assessment of the relationships in variables.

The model estimation reveals the tendency of returns to restore equilibrium via the errorcorrection mechanism. The model also shows reversals in short-run returns, and a slower recovery rate to equilibrium by the returns of small stocks. A significant negative (positive) impact of changes in $\mathrm{IVol}$ risk on short-run returns at the lower (upper) quantiles of its conditional distribution indicates that while the changes in $\mathrm{IVol}$ risk create buying and selling opportunities among the low performing stocks, investments in high performing stocks benefit from such changes. An increasing trend in the quantile dependent marginal effect of changes in IVol risk on short-run returns implies a quadratic relationship in the levels of the two series. The significant marginal effects of changes in idiosyncratic volatility and its one period lagged values on shortrun returns at many quantiles support persistence in idiosyncratic risk, and their reversing signs provide an evidence of reversion in short-run returns. While the short-run responses of returns to changes in ln $\mathrm{bm}$ are positive, their reaction to persistence in changes in IVol cause the reversal process - a pattern that could be interpreted as the effect of risk-averse investors' efforts to adjust their investment moves to take advantage of value-growth opportunities and reduce exposure to idiosyncratic risk. The quantile regression estimation within the size-sorted portfolios reveals that the quadratic form of the long-run idiosyncratic risk-return relationship is sensitive to the market capitalization of firms, and highlights the importance of the role played by the market capitalization of stocks in the stock market.

In summary, the findings in this paper enhance our understanding of the return-reversal process and the rational equilibrium paradigm of CGW (1993) via explanations based on an econometric model of panel error-correction, and the role played by persistence in idiosyncratic risk. The applicability of the quantile regression methodology within the modelling framework of this paper facilitates the unfolding of several new relationship patterns, while confirming some known results.

The remainder of the paper is organised as follows: In Section 2 we provide detailed literature review covering the two strands of literature flagged in the introduction. Section 3 describes the data and the modelling framework. Section 4 reports the findings of the analysis and implications of the results, and the paper concludes by summarising the main results in Section 5.

\section{LITERATURE REVIEW}

In this section, we limit our discussion to papers that are closely related to our work and belong to the two strands of literature this paper connects to. The generating mechanism of the return-reversals that produces large abnormal profits under some stock market trading strategies has intrigued researchers. According to the literature (e.g. Sims, 1984) the stock prices should display a martingale behaviour over short time intervals, since systematic changes in fundamental valuations should not occur over short time horizons to impact prices. However, empirical studies report evidence of predictability in stock returns. Lehmann (1990), following the contrarian trading strategy, finds the existence of return-reversals at the weekly horizons; portfolios of stocks that had positive (negative) returns in one week typically had negative (positive) returns in the next week. He describes this phenomenon as a result of an imbalance in the market for 
short-run liquidity. Jegadeesh (1990) reports the presence of significantly negative first-order serial correlation in monthly returns as an evidence of return-reversals at the monthly frequencies. Some researchers (DeBondt and Thaler, 1985; Fama and French, 1988) observed such variation patterns over three-to-ten year intervals.

Following the relative strength trading strategy for forming portfolios, Jegadeesh and Titman (1993) observe significant positive returns ${ }^{2}$ (the momentum continuation) over 3 to 12 month holding periods followed by momentum reversals. They offer two possible interpretations of their results: (i) 'the relative strength trading strategy moves the prices away from their long-run values temporarily and thereby cause prices to overreact'; (ii) 'it is possible that the market underreacts to information about the short-term prospects of firms but overreacts to information about their longterm prospects'. They explain that this profitability can neither be attributed to the systematic risk, nor to the lead-lag effects that result from delayed stock price reactions to common factors. They add that it is more likely linked to delayed price reactions to firm-specific information, and that a more sophisticated model of investor behaviour is needed for understanding this observed pattern in returns. For the US data, Arena et al. (2008) report observing high idiosyncratic volatility stocks yielding higher momentum returns and displaying quicker and larger reversals.

CGW (1993) describe the return-reversal process and the associated high abnormal returns resulting from the short-run contrarian strategies via the rational equilibrium paradigm. They explain that shifts in demand by non-informational (i.e., liquidity) traders that accompany high trading volume cause price deviations from the fundamentals. This offers profit opportunities to risk-averse liquidity suppliers - the market makers, and the absorption of liquidity demand by market makers causes the prices to revert. Thus, the lack of liquidity moves stock prices away from the fundamentals and the supply of liquidity induces return reversals. CGW (1993) offer the above explanation based on observing a large trading volume (using turnover as its proxy) associated with a relatively large first order negative autocorrelation in returns, and a significant interaction between the trading volume and the first order autocorrelation in returns. They add that the risk-aversion of the market plays a very influential role in the return-reversal phenomenon; the relationship between volume and autocorrelation of returns weakens as the persistence in riskaversion increases.

Chordia et al. (2005) assert that the level of correction in liquidity determines the speed of the process integrating information into the stock prices. If stock prices move away from the fundamentals, liquidity will influence how much and how fast the prices revert. Applying the concept of illiquidity, Averamon et al. (2006) report observing reversals in weekly and monthly stock returns that are mainly confined to the loser stocks - the stocks with negative returns in the past week or month. Controlling for volume, they find that the return reversals are more dominant in less liquid stocks. At the weekly (monthly) frequency, they observe high (low) turnover stocks exhibiting higher negative serial correlation and therefore, more reversals than low (high) turnover stocks, and thus confirming the existence of rational equilibrium paradigm of CGW (1993).

Lu-Andrews and Glascock (2014) study the price reversal behaviour around the strong market events using stock portfolios sorted by liquidity and/ or size. They find that large liquid stocks have a stronger reaction to market shocks and experience a faster price reversal following the shocks than do small illiquid stocks. Their study also reveals that larger firms with larger betas as well as high liquidity seem to experience a stronger reversal when associated with market events, and that small illiquid stocks have higher idiosyncratic volatility risk than larger liquid stocks.

\footnotetext{
The attractiveness of positive returns over short to medium time horizons from following the momentum strategy in the US motivated many researchers to evaluate the performance of this strategy in markets outside US. Rouwenhorst (1998) apply the momentum strategy to 12 European markets, and observe results similar to Jagedeesh and Titman (1993). Connolly and Stivers (2003) study momentum reversals observed in individual stocks in the US, Japan and the UK stock markets, and find that the reversals are associated with low turnovers. Drew et al. (2007) find the existence of momentum continuation followed by reversals in the Australian stock market; Hameed and Kusnadi (2002) apply this strategy to six stock markets in the Pacific Basin and do not find its prevalence.
} 
It follows from the discussion in the preceding paragraphs that underlying the price movements, there exists a long-run equilibrium process around the fundamental valuations of stocks. Prices deviate from the fundamentals temporarily and then move back towards the fundamentals causing return reversals and creating buying-selling opportunities. It should be noted that all of the above quoted studies, which were devoted to the understanding of the shortrun return-reversal phenomenon within the existence of a rational equilibrium paradigm, utilized US data. To the best of our knowledge, our study is the first one outside the US to show the shortrun return-reversal process linked to the existence of an equilibrium state based on novel evidence backed by robust econometric methodology. We, using the Australian data and keeping in view the findings of Levy (1978), build on the remarks of Jegadeesh and Titman (1993) and employ idiosyncratic volatility risk, book-to-market ratios and market capitalization of stocks as the firmspecific information factors, as opposed to liquidity and/ or volume used in earlier studies. While the idiosyncratic volatility contains fundamental factors as well as the non-fundamentals (Jiang and Lee, 2006), the book-to-market ratios represent valuations of stock prices by informed and ill-informed traders at a given point in time. The importance of the effect of market capitalization of stocks on returns and its relationship with idiosyncratic volatility risk is well known in the finance literature.

This paper also links to a large literature on asset pricing, where the interest is to explore the form of the idiosyncratic risk-return relationship. Given that the theoretical work of Levy (1978) shows that idiosyncratic risk affects equilibrium asset prices if investors do not hold a fully diversified portfolio of assets, we expect idiosyncratic risk to play a dominant role in our investigation. Campbell et al. (2001) and Goyal and Santa-Clara (2003) identify the idiosyncratic risk as constituting a major portion of the total risk. Some studies (e.g., Fu, 2009; Malkiel and Xu, 1997) find a positive relationship between the idiosyncratic volatility risk and the expected returns in the cross section, and thus provide an empirical support to the theory proposed by Merton (1987). However, the empirical studies of Ang et al. $(2006,2009)$ report a negative relationship in predictive models built on daily data over monthly frequencies.

$\mathrm{Fu}$ (2009) argues that idiosyncratic risk-return relationship is contemporaneous and attributes the anomalous negative idiosyncratic risk-return relation in Ang et al. (2006) to the use of a predictive model linking realized idiosyncratic risk from the previous month to the next month's returns. He asserts that Ang et al. (2006) implicitly assume that the idiosyncratic volatility time series can be approximated by a random walk process for setting up a predictive model. Ang et al. (2009), p.2, para 5, defend their stance by stating that 'they observe persistence in the idiosyncratic volatility series, and expect their lagged measure of idiosyncratic volatility risk to be correlated with the future idiosyncratic volatility risk that agents might assess in determining expected returns'. Many other studies (e.g., Hur, 2010; Jiang and Lee, 2006; Nath and Brooks, 2015) report observing persistence in idiosyncratic volatility series.

Campbell et al. (2001) observe a positive deterministic trend in idiosyncratic firm-level volatility based on US data for the period 1964-1997. Bekaert et al. (2008, Table 2) dispute this assertion, and show that the trend tests are quite sensitive to the sample period used (e.g., 1964-1997 v/s 1964-2005). They further add that if a time series exhibits time trend over a part of its sample path, it is likely characterised by near non-stationary behaviour. As per Jiang and Lee (2006), the power of the one-step predictive regressions methodology used for studying the relationship between future returns and volatility is compromised if the explanatory variable is persistent. They state that if idiosyncratic risk is persistent, then instead of using the raw idiosyncratic measure values, serially uncorrelated innovations in idiosyncratic volatility must be added in the model as regressors. Campbell and Yogo (2006) explain that 'Conventional tests of the predictability of stock returns could be invalid, that is reject the null too frequently, when the predictor variable is persistent and its innovations are highly correlated with returns'. It follows from the above discussion that it is likely for an idiosyncratic volatility series to be persistent or 
non-stationary in some sampling periods or study samples ${ }^{3}$, and if it does it is important that the modelling process accommodates such data features.

$\mathrm{Fu}$ (2009) explains that the negative relation in Ang et al. (2006) study is due to a subset of small stocks with high idiosyncratic volatility that earn high returns in the month of high idiosyncratic volatility. The high returns reverse in the next month causing negative abnormal returns. Huang et al. (2010) attribute the negative relation in Ang et al. (2006) to the 'omission of the previous month's stock returns as a regressor in the cross-sectional regressions involving daily data. It results in a negatively biased coefficient on idiosyncratic risk, especially if one uses realized idiosyncratic volatility in the previous month as a proxy for idiosyncratic risk. This bias is largely attributed to the negative serial correlation in monthly returns and the positive contemporaneous relation between realized idiosyncratic volatility and stock returns'. Fu (2009) and Huang et al. (2010) studies also assert that using a more accurate estimate of idiosyncratic risk, e.g., an EGARCH estimate based on monthly data, produces a positive relationship.

The motivation in the investigations of Fu (2009) and Huang et al. (2010) is the assumption that the relationship between idiosyncratic risk and stock returns ought to be contemporaneous and positive, or else the model used (e.g., the predictive models of Ang et al. 2006, 2009) for linking the variables is either not correct, or the estimate of idiosyncratic risk is inferior. Recently, Nath and Brooks (2015) resolved the issue of inferior estimate flagged in $\mathrm{Fu}(2009)$ and Huang et al. (2010) papers by building predictive models on daily data and showing the emergence of identical results from employing the idiosyncratic risk estimates used in Ang et al. (2006) and Fu (2009) studies.

According to the literature on return-reversals cited above, the return-reversal process if it exists is not bad as it creates buying-selling and profit opportunities for investors. The interest is to understand what causes return-reversals, and if there exists an equilibrium state governed by fundamentals maintaining balance via reversions. This paper supports the notion of predictive models ${ }^{4}$, where explanatory variables are estimated or recorded in a period prior to the period of realizing stock returns. From a decision or a policy maker's perspective, models with predictive element have a lot more appeal than a static single or same period models depicting contemporaneous relationships. A model that does not offer opportunity to investors to weigh their investment strategy in short to medium term time frame is of limited use. The time between buying and selling of stock (s) to realize returns on an investment is never zero, and therefore a model representing contemporaneous relation cannot serve well. Moreover, like Ang et al. (2006), we find the idiosyncratic volatility risk to be highly persistent that justifies the use of lagged idiosyncratic risk for predicting future stock returns. Jegadeesh (1990), Lehmann (1990) and many others form portfolios of stocks on past information - the so called predictive portfolios, and observe the returns on these stocks at a future date.

Against this background, we build our modelling frame work to assess if persistence in idiosyncratic volatility risk is a proxy for short-run return-reversals in stock market trading.

\footnotetext{
Moreover, the persistence patterns observed from using daily and monthly values are likely to be different from the annualized values due to smoothing.

4 All tests of the Fama and MacBeth (1973) model are predictive in nature in the sense that estimates of the beta and non-beta risks, used as explanatory variables to explain expected returns, are computed from data for a period prior to the time of the stock returns. Referring to the 'Normative Theory' of Markowitz (1959) they add that " As a normative theory the model only has content if there is some relationship between future returns and estimate of risk that can be made on the basis of current information". In the context of introducing the intertemporal capital asset pricing model, Merton (1973) comments that although the CAPM (capital asset pricing model) is a static single-period model, it has been treated to hold inter-temporally. He adds that as per Merton (1971) work, "the portfolio behavior for an intertemporal maximizer will be significantly different when he faces a changing investment opportunity set instead of a constant one". Thus, if a model is to be based on reasonable assumptions, it must be intertemporal to capture the effects that would not show up in a static single-period model.
} 


\section{DATA AND EMPIRICAL FRAMEWORK}

Data for the period from January 2001 to August 2010 are downloaded from Datastream. It consists of the end of the day prices of stocks trading on the Australian Securities Exchange (ASX), All Ordinaries Index as a representative of a general market portfolio, market capitalization (firm size), book-to-market value of each stock, and 30-day Cash rate as set by Reserve Bank of Australia Board at each monthly meetings as a proxy for the daily risk free rate of return. Stocks that did not trade for $20 \%$ or more days during the sampling period, had missing data on one or more important variables or did not trade for 100 consecutive days are excluded from our study sample. Due to the global financial crisis in 2007-2008 some companies merged or failed to exist and did not meet our selection criteria. The sample ends up with 207 stocks representing all 12 sectors of S \& P GICS (Global Industry Classification System) adopted by the ASX in 2002. These stocks traded over the entire length of the study period, and experienced expansion and contraction periods of the Australian economy.

\subsection{Measuring idiosyncratic risk and setting up panel data structure}

The idiosyncratic volatility risk is measured relative to the Fama and French (1993) threefactor (FF-3) model as in Ang et al. (2006, 2009) using forward rolling windows of 20 days. In empirical finance it is a common practice to use forward rolling windows and daily data within a calendar month for estimating time varying parameters over monthly horizons (e.g., 1/0/1 strategy in Ang et al., 2006, 2009). Many studies (e.g., Fu, 2009) require a stock to trade for a minimum of 15 days within a month for inclusion in the sample; the maximum number of days a stock can trade in a calendar month is 23 . In this instance, the estimation sample size within a month can vary between 15 and 23 . We depart from this practice and instead use 20-day trading-blocks for fitting the FF-3 model to estimate the idiosyncratic volatility. The logic here is that traders following the technical analysis rules may not want to confine to calendar months framework; they use moving averages based on daily data for gauging the price movements in stocks, and may wish to know the idiosyncratic risk estimate over the same time horizon. The 20 day trading regime roughly corresponds to a month's trading and allows an easy comparison with studies that employ calendar months based time horizons. Moreover, this design can accommodate estimation and holding window sizes of any desired length in days (cf., Nath and Brooks, 2015 ${ }^{6}$ ). While, the use of rolling windows in estimation allows the parameters of the process to evolve over time placing little constraint on the evolutionary structure, the choice of a larger estimation sample versus a smaller sample in rolling windows depends on the desire to balance the bias and variance likely to result from a stationary versus a nonstationary process. Fama and MacBeth (1973) explain the choice between a larger and a smaller estimation sample as 'a desire to balance the statistical power obtained with a large sample from a stationary process against the potential problems caused by any non-consistency of $\beta_{i}$. As a number of time series employed in this paper display nonstationary behaviour, it is reasonable to use 20 days as the estimation window size.

We follow the two-stage procedure of Fama and MacBeth (1973) for setting up a panel data structure using predictive models that allows a stock to have time varying betas, idiosyncratic risk and other important stock specific characteristics. In the first stage, we compute the idiosyncratic risk applying the least squares estimation ${ }^{7}$ of FF-3 factor model specified in Eq. (1) for each stock using a time series of 20 days' excess returns, excess market returns and Fama and French (1993)

Referring to the reported abnormal profits generated from following the contrarian as well as the relative strength trading strategies, Jegadeesh and Titman (1993) explain that one possible reason for this occurrence could be due to the differences between the time horizons used in the trading rules examined in academic papers and those used in practice.

6 Nath and Brooks (2015) use estimation and holding windows of different sizes in days for assessing the robustness of their models.

Nath and Brooks (2015) show that identical results emerge from using the least squares and the GARCH based measures of idiosyncratic volatility estimated using daily data. 
factors. Specifically, the idiosyncratic risk $(\mathrm{IVol})$ for stock $i$ over a 20 -day estimation period is computed as the standard deviation of the regression residuals $\left(\varepsilon_{i d}\right)$ in the FF-3 factor model

$$
y_{i d}=\alpha_{i}+\beta_{M K T, i} r_{m d}+\beta_{S B M, i} S B M_{d}+\beta_{H M L, i} H M L_{d}+\varepsilon_{i d}
$$

In Eq (1), $y_{i d}$ is the excess return for stock $i, r_{m d}$ the excess market return, and $S M B_{d}$ and $H M L_{d}$ the Fama and French (1993) daily factors for the Australian data on day $d$. Since each stock traded for 20 days in the estimation phase, an adjustment of multiplying the standard deviation of residuals by the square root of the number of days a stock traded, as implemented in some past studies (e.g., Fu (2009) is not required. This estimation phase produces estimates of a stock's beta-risk, Fama and French factor loadings as well as idiosyncratic risk. A stock's median market capitalization, expressed in natural $\log$ (lnsize), and the natural log of the median book-to-market $(\operatorname{lnbm})$ values are also recorded over this 20-day time-block. This information forms values of the explanatory variables. Next a stock's average excess return over the next 20 days is computed and used as the response variable value. The process is repeated for each of the 207 stocks; this forms one panel. The estimation window is moved forward by 20 days, and the process is repeated over the entire data of 2503 trading days which creates 118 panels comprising information on the dependent and the independent variables for each of the 207 stocks. This completes the first stage of the procedure.

Estimates from the first stage are used in the second stage for testing and establishing relationships between the realized excess stock returns and the right-hand-side variables, which include $I V o l$, FF-3 factor loadings, lnsize and $\operatorname{lnbm}$ as firm characteristics. We use subscripts $i, k$ and $t$ to represent the stock, the 20-day block and the panel numbers, respectively. For forming $T$ panels, $(T+1) 20$-day blocks are required; thus $k=t+1$, for $\mathrm{t}=1,2, \ldots, T$. The crosssectional relationship between the realized excess stock returns in period $(t+1)$ and the realized idiosyncratic risk and other explanatory variable values observed in period $t$ is evaluated in each panel using equation (2).

$$
\begin{gathered}
\boldsymbol{R}_{i, k, t}=\gamma_{0 t}+\gamma_{1 t} \beta_{M K T, i, k-1, t}+\gamma_{2 t} \beta_{S B M, i, k-1, t}+\gamma_{3 t} \beta_{H M L, i, k-1, t}+ \\
+\gamma_{4 t} I V o l_{i, k-1, t}+\sum_{l=5}^{L} \gamma_{l t} X_{l, i, k-1, t}+u_{i, k, t} \\
i=1,2, \ldots, N, k=t+1, t=1, \ldots, T .
\end{gathered}
$$

In Eq. (2), $\boldsymbol{R}_{i, k, t}$ is the average excess return for stock $i$ in panel $t$ realized in time block $k$. All right-hand-side variables for panel $t$ are observed in time block $(k-1)$; betas represent the FF-3 factor loadings for stock $i, I \mathrm{Vol}$ - the idiosyncratic risk proxy, $X_{i, k-1, t}$ - the explanatory variables lnsize and $l n b m$, and $u_{i, k, t}$ - the error term. The use of subscript $k$ in relation (2) was to stress the point that the returns are observed in a time-period (20-day block) later than the right-handside variables values. But once the panels are formed we drop subscript $k$ from the subsequent equations. Thus, equation (2) is an equivalent of stage-two predictive relationship model in Ang et al. (2009, Eq. 4) and Fu (2009, Eq. 6), which also include Insize and Inbm as explanatory variables alongside the FF-3 factor loadings. The logic here is that if FF-3 factor betas are able to explain the cross section of expected returns, then the coefficients of lnsize and lnbm would not be significantly different from zero. Thus, the inclusion of lnsize and $\ln b m$ as explanatory variables in model alongside FF-3 factors serves as a test of mis-specification of the model. The time series of estimates for each coefficient from equation (2) are pooled and the $t$-test statistics are formed using the Fama-MacBeth (1973) procedure as, 


$$
\begin{gathered}
t_{\gamma(t)}=\widetilde{\gamma}_{l} / \widetilde{\sigma}_{l}, \text { where } \\
\widetilde{\gamma}_{l}=\sum_{t=1}^{T} \hat{\gamma}_{l t} / T \\
\text { and } \widetilde{\sigma}_{l}^{2}=\frac{1}{T(T-1)} \sum_{t=1}^{T}\left(\hat{\gamma}_{l t}-\widetilde{\gamma}_{l}\right)^{2}
\end{gathered}
$$

These $t$-statistics follow Student's $t$-distribution with $(T-1)$ degrees of freedom. These second stage estimates represent the long-run relationship coefficients between the levels of the expected returns and the explanatory variables series, and serve as the benchmark for checking the subsequent results.

Before executing the second stage of estimation we check all series for persistence and unit roots. The time series plots (not provided in paper) and the autocorrelations in time series of IVol, lnsize and $\operatorname{lnbm}$ show high persistence. Table 1 displays summary statistics of autocorrelations observed in $\mathrm{IVol}$ series of 207 stocks. To conserve space summary of autocorrelations in others series is not reported.

Table 1

Persistence in idiosyncratic volatility: This table presents summary statistics of autocorrelations in idiosyncratic volatility time series of stocks. The reported figures are obtained by first calculating the autocorrelations up to lag 10 for each stock, and then compiling the summary measures. An absolute value greater than or equal to 0.180433 is

\begin{tabular}{|c|c|c|c|c|c|c|c|c|c|c|}
\hline & \multicolumn{10}{|c|}{ Lag length } \\
\hline & 1 & 2 & 3 & 4 & 5 & 6 & 7 & 8 & 9 & 10 \\
\hline Mean & 0.459 & 0.393 & 0.365 & 0.342 & 0.308 & 0.277 & 0.240 & 0.205 & 0.191 & 0.162 \\
\hline Median & 0.451 & 0.395 & 0.354 & 0.345 & 0.297 & 0.283 & 0.242 & 0.204 & 0.189 & 0.168 \\
\hline Max & 0.907 & 0.839 & 0.797 & 0.757 & 0.727 & 0.663 & 0.581 & 0.511 & 0.504 & 0.452 \\
\hline Q3 & 0.593 & 0.523 & 0.491 & 0.479 & 0.426 & 0.381 & 0.338 & 0.306 & 0.287 & 0.242 \\
\hline Q1 & 0.367 & 0.270 & 0.230 & 0.213 & 0.193 & 0.151 & 0.124 & 0.091 & 0.085 & 0.058 \\
\hline $10^{\text {th }}$ percentile & 0.228 & 0.151 & 0.147 & 0.117 & 0.110 & 0.070 & 0.054 & 0.012 & 0.013 & -0.014 \\
\hline
\end{tabular}
significant at 5\% level of significance. The bolded values represent nonsignificant autocorrelations. Q1 represents the first quartile and Q3 the $3^{\text {rd }}$ quartile.

It follows from Table 1 that the idiosyncratic volatility series for the majority of the stocks show persistence up to many lags. Of particular interest are the first quartile and the $10^{\text {th }}$ percentile values of the autocorrelations. While the first quartile values imply that at least $75 \%$ of the stocks have persistent idiosyncratic volatility series that show dependence up to 5 lags, the $10^{\text {th }}$ percentile values indicate that at least $90 \%$ of the idiosyncratic volatility series possess the first order lag dependence. It is, thus, of interest to further investigate the nature of this dependence.

\subsection{Testing idiosyncratic volatility and other series for random walks and panel cointegration}

It is well known in the econometrics literature (e.g., Engle and Granger 1987) that meaningful long-run relations cannot be formed using nonstationary $I(p)$ series, where $I(p)$ stands for integration of order $p$, unless the series are cointegrated. A nonstationary $I(1)$ series can be made stationary by differencing once. Moreover, if a relatively less persistent return series is 
regressed on the first lag of some highly persistent predictors, the predictability could often be missed due to the persistence imbalance (Ren et al., 2015). We, therefore, start by testing the time series of idiosyncratic volatility $(I V o l)$, squared idiosyncratic volatility $\left(I V o l^{2}\right)^{8}$, Insize, $\operatorname{lnbm}$ and the realized excess returns $\mathscr{R}$ for unit roots. The commonly used ADF (Augmented Dickey Fuller) tests of unit root have unit root as the null. These tests are known to suffer from lack of power and size distortion. It is, therefore, a common practice to use the KPSS (Kwiatkowski, Phillips, Schmidt, and Shin) family of tests, which have 'No unit root' as the null, in conjunction with the ADF tests for confirmatory analysis to make sure that the conclusion is not a consequence of a test that lacks power. Two ADF tests ( a test of pure random walk (RW), and RW with a drift) and two KPSS tests (involving constant only, and constant and linear trend as exogenous variables) are employed for this purpose. Table 2 reports a summary statistics of slope estimates from performing the ADF and the KPSS tests on the time series of $\mathrm{IVol} \mathrm{IVol}^{2}$, lnsize, $\operatorname{lnbm}$ and $\mathscr{R}$ for each of the 207 stocks. In this reporting, the use of average slope and average test-statistic value is avoided as averaging masks pattern. The listed Dickey-Fuller and KPSS critical values are taken from Greene (2012); the starred critical values for the ADF tests are generated by Eviews software for our time series of length 118. The last column in Table 2 lists the percentage of stocks for which the hypothesis of unit root is accepted. The ADF and the KPSS tests confirm that the time series of $\mathrm{IVol}_{\text {, }} \mathrm{VOl}^{2}$, lnsize and $\operatorname{lnbm}$ for the majority of the stocks have unit roots (i.e., follow random walks) and that the first order differencing makes them stationary. However, the percentage of excess returns series possessing a unit root is very small.

Table 2

Tests of unit root: Table parts (a) and (b) present two ADF tests, the test of a pure Random Walk and a test of Random Walk with a drift. The reported figures are the summary statistic values of the slope estimates and their associated test statistic values (in parentheses) from applying the ADF tests to time series of $I V o l, I V o l^{2}, \operatorname{lnsize}, \operatorname{lnbm}$ and $\mathscr{R}$ for each of the 207 stocks. The bottom panel of table part (a) displays the results of applying a pure Random Walk test to first differences of series. The last column shows the percentage of stocks for which the tests confirmed unit root presence. Table parts (c) and (d) report the summary statistic values from applying the two KPSS tests of stationarity to time series of $I V o l, I V o l^{2}$, lnsize, $\operatorname{lnbm}$ and $\mathscr{R}$ for each of the 207 stocks.

(a) ADF test of a pure Random Walk

\begin{tabular}{|c|c|c|c|c|c|c|c|c|}
\hline Series & Min & $\begin{array}{c}25^{\text {th }} \\
\text { smallest }\end{array}$ & $\begin{array}{c}50^{\text {th }} \\
\text { smallest }\end{array}$ & Mid-value & $\begin{array}{c}50^{\text {th }} \\
\text { largest }\end{array}$ & $\begin{array}{c}25^{\text {th }} \\
\text { largest }\end{array}$ & Max & $\begin{array}{l}\text { Percent } \\
\text { accepted } \\
\text { unit root }\end{array}$ \\
\hline \multicolumn{9}{|c|}{ Test result for levels } \\
\hline IVol & $\begin{array}{l}-0.09855 \\
(-3.2206)\end{array}$ & $\begin{array}{l}-0.04347 \\
(-1.5398)\end{array}$ & $\begin{array}{l}-0.03713 \\
(-1.1806)\end{array}$ & $\begin{array}{l}-0.03818 \\
(-0.8903)\end{array}$ & $\begin{array}{l}-0.02393 \\
(-0.7147)\end{array}$ & $\begin{array}{l}-0.01949 \\
(-0.5916)\end{array}$ & $\begin{array}{l}-0.00637 \\
(-0.1872)\end{array}$ & 98.55 \\
\hline $\mathrm{IVol}^{2}$ & $\begin{array}{l}-0.46557 \\
(-7.2201)\end{array}$ & $\begin{array}{l}-0.40192 \\
(-2.8807)\end{array}$ & $\begin{array}{l}-0.15434 \\
(-2.3082)\end{array}$ & $\begin{array}{l}-0.15619 \\
(-1.8249)\end{array}$ & $\begin{array}{l}-0.09881 \\
(-1.4928)\end{array}$ & $\begin{array}{l}-0.08569 \\
(-1.2920)\end{array}$ & $\begin{array}{l}-0.08084 \\
(-0.7962)\end{array}$ & 84.54 \\
\hline lnsize & $\begin{array}{l}-0.05758 \\
(-3.1446)\end{array}$ & $\begin{array}{l}-0.01466 \\
(-1.6118)\end{array}$ & $\begin{array}{l}-0.00596 \\
(-1.1194)\end{array}$ & $\begin{array}{l}-0.00069 \\
(-0.2712)\end{array}$ & $\begin{array}{c}0.00082 \\
(0.6664)\end{array}$ & $\begin{array}{c}0.00359 \\
(1.0691)\end{array}$ & $\begin{array}{l}0.00154 \\
(2.7287)\end{array}$ & 99.03 \\
\hline $\operatorname{lnbm}$ & $\begin{array}{c}-0.49544 \\
(-10.2110)\end{array}$ & $\begin{array}{l}-0.09650 \\
(-2.4940)\end{array}$ & $\begin{array}{l}-0.05441 \\
(-2.0449)\end{array}$ & $\begin{array}{l}-0.02706 \\
(-1.3127)\end{array}$ & $\begin{array}{l}-0.00924 \\
(-0.7543)\end{array}$ & $\begin{array}{l}-0.00260 \\
(-0.2765)\end{array}$ & $\begin{array}{c}0.00553 \\
(0.6186)\end{array}$ & 88.89 \\
\hline $\mathscr{R}$ & $\begin{array}{l}-1.24810 \\
(-7.8574)\end{array}$ & $\begin{array}{l}-0.82655 \\
(-5.1858)\end{array}$ & $\begin{array}{l}-1.12151 \\
(-4.8526)\end{array}$ & $\begin{array}{l}-1.04496 \\
(-4.4244)\end{array}$ & $\begin{array}{l}-0.69176 \\
(-3.8975)\end{array}$ & $\begin{array}{l}-0.74229 \\
(-3.6121)\end{array}$ & $\begin{array}{l}-0.40310 \\
(-2.0991)\end{array}$ & 0.48 \\
\hline
\end{tabular}

Nath and Brooks (2015) provide lead for building models using $I V o l^{2}$ by showing that the inclusion of predictor $I V o l^{2}$ does not change the forms of relationships between expected excess returns and each of the explanatory variables, but improves Adj-R ${ }^{2}$, and hence we test $I V o l^{2}$ series for unit root. However, if $\mathrm{IVol}$ is nonstationary, $\mathrm{IVol}^{2}$ will be nonstationary as well. The test results are displayed for the sake of completeness. 
Test result for first differences

\begin{tabular}{lccccccccc}
\hline IVol & -3.65730 & -3.45304 & -2.90054 & -2.67854 & -2.41699 & -2.02900 & -1.09786 & \\
& $(-10.8320)$ & $(-8.0852)$ & $(-7.6847)$ & $(-6.9771)$ & $(-6.2978)$ & $(-5.9368)$ & $(-4.0604)$ & 0 \\
IVol $^{2}$ & -3.63600 & -3.32084 & -3.20600 & -3.07784 & -2.58764 & -2.11705 & -1.14775 & \\
& $(-13.7332)$ & $(-8.3569)$ & $(-7.9434)$ & $(-7.0847)$ & $(-6.3069)$ & $(-5.8134)$ & $(-4.1277)$ & 0 \\
Insize & -0.76640 & -0.90603 & -1.01609 & -0.87647 & -0.87488 & -0.73619 & -0.39510 & & \\
& $(-6.2384)$ & $(-5.1218)$ & $(-4.8919)$ & $(-4.6288)$ & $(-4.2769)$ & $(-4.0391)$ & $(-3.0325)$ & 0 & \\
Inbm & -1.43999 & -1.12459 & -1.10602 & -0.84986 & -0.77201 & -0.89744 & -0.58998 & \\
& $(-6.8551)$ & $(-5.5746)$ & $(-5.2987)$ & $(-4.8390)$ & $(-4.4695)$ & $(-4.2051)$ & $(-3.5448)$ & 0 \\
\multirow{2}{*}{} & -3.80863 & -3.56077 & -3.84020 & -3.42604 & -3.48375 & -2.94288 & -2.19731 & & \\
& $(-11.2024)$ & $(-8.9827)$ & $(-8.4502)$ & $(-7.7993)$ & $(-7.1798)$ & $(-6.8773)$ & $(-5.6106)$ & 0 \\
\hline
\end{tabular}

Critical values (at 1\%) of ADF test of pure Random Walk

(Source: Econometrics Analysis, 2012, William H. Greene)

\begin{tabular}{lccccc}
\hline $\mathrm{n}$ & 25 & 50 & 100 & infinity & $118^{*}$ \\
Cr. value & -2.66 & -2.62 & -2.6 & -2.58 & -2.5847 \\
\hline \hline
\end{tabular}

(b) ADF test of Random Walk with a drift

\begin{tabular}{|c|c|c|c|c|c|c|c|c|}
\hline Series & Min & $\begin{array}{c}25^{\text {th }} \\
\text { smallest }\end{array}$ & $\begin{array}{c}50^{\text {th }} \\
\text { smallest }\end{array}$ & Mid-value & $\begin{array}{c}50^{\text {th }} \\
\text { largest }\end{array}$ & $\begin{array}{c}25^{\text {th }} \\
\text { largest }\end{array}$ & Max & $\begin{array}{c}\text { Percent } \\
\text { accepted } \\
\text { unit root }\end{array}$ \\
\hline \multicolumn{9}{|c|}{ Test result for levels } \\
\hline IVol & $\begin{array}{l}-0.88540 \\
(-8.2734)\end{array}$ & $\begin{array}{l}-0.49583 \\
(-3.8371)\end{array}$ & $\begin{array}{l}-0.47851 \\
(-3.5026)\end{array}$ & $\begin{array}{l}-0.27218 \\
(-2.8485)\end{array}$ & $\begin{array}{l}-0.20580 \\
(-2.2993)\end{array}$ & $\begin{array}{l}-0.12333 \\
(-2.0161)\end{array}$ & $\begin{array}{l}-0.14599 \\
(-1.5793)\end{array}$ & 75.85 \\
\hline IVol2 & $\begin{array}{c}-0.96665 \\
(-11.6337)\end{array}$ & $\begin{array}{l}-0.73038 \\
(-4.2634)\end{array}$ & $\begin{array}{l}-0.51431 \\
(-3.7264)\end{array}$ & $\begin{array}{l}-0.52036 \\
(-3.1114)\end{array}$ & $\begin{array}{l}-0.23401 \\
(-2.5683)\end{array}$ & $\begin{array}{l}-0.28877 \\
(-2.2982)\end{array}$ & $\begin{array}{l}-0.11557 \\
(-1.5765)\end{array}$ & 69.08 \\
\hline lnsize & $\begin{array}{c}-0.93986 \\
(-53.9693)\end{array}$ & $\begin{array}{l}-0.42579 \\
(-8.6191)\end{array}$ & $\begin{array}{l}-0.30217 \\
(-5.8075)\end{array}$ & $\begin{array}{l}-0.04622 \\
(-3.4471)\end{array}$ & $\begin{array}{l}-0.05065 \\
(-1.7862)\end{array}$ & $\begin{array}{l}-0.03243 \\
(-1.3002)\end{array}$ & $\begin{array}{l}-0.00098 \\
(-0.0678)\end{array}$ & 51.21 \\
\hline $\operatorname{lnbm}$ & $\begin{array}{c}-0.56851 \\
(-12.9391)\end{array}$ & $\begin{array}{l}-0.26997 \\
(-4.8957)\end{array}$ & $\begin{array}{l}-0.10497 \\
(-3.3259)\end{array}$ & $\begin{array}{l}-0.08669 \\
(-2.4912)\end{array}$ & $\begin{array}{l}-0.04665 \\
(-1.8429)\end{array}$ & $\begin{array}{l}-0.03949 \\
(-1.4233)\end{array}$ & $\begin{array}{c}0.01560 \\
(0.6427)\end{array}$ & 78.26 \\
\hline $\mathscr{R}$ & $\begin{array}{l}-1.24041 \\
(-7.7577)\end{array}$ & $\begin{array}{l}-1.02665 \\
(-5.3794)\end{array}$ & $\begin{array}{l}-1.10111 \\
(-4.9292)\end{array}$ & $\begin{array}{l}-0.73556 \\
(-4.4775)\end{array}$ & $\begin{array}{l}-0.71136 \\
(-3.9095)\end{array}$ & $\begin{array}{l}-0.85219 \\
(-3.6642)\end{array}$ & $\begin{array}{l}-0.56740 \\
(-2.8874)\end{array}$ & 6.3 \\
\hline
\end{tabular}

Critical values (at $1 \%$ ) of ADF test of Random Walk with drift

(Source: Economertics Analysis, 2012, William H. Greene)

\begin{tabular}{lccccc}
\hline $\mathrm{n}$ & 25 & 50 & 100 & infinity & $118^{*}$ \\
Cr. Value & -3.75 & -3.59 & -3.5 & -3.42 & -3.4891 \\
\hline \hline
\end{tabular}


(c) KPSS test of stationarity with intercept only

\begin{tabular}{|c|c|c|c|c|c|c|c|c|}
\hline Series & Min & $\begin{array}{c}25^{\text {th }} \\
\text { smallest }\end{array}$ & $\begin{array}{c}50^{\text {th }} \\
\text { smallest }\end{array}$ & Mid-value & $50^{\text {th }}$ largest & $25^{\text {th }}$ largest & $\operatorname{Max}$ & $\begin{array}{l}\text { Percent } \\
\text { accepted unit } \\
\text { root at } 5 \%\end{array}$ \\
\hline \multicolumn{9}{|c|}{ LM Test statistic values for levels; } \\
\hline IVol & 0.06375 & 0.17526 & 0.24229 & 0.38158 & 0.57568 & 0.66234 & 1.05578 & 37 \\
\hline $\mathrm{IVol}^{2}$ & 0.05584 & 0.16260 & 0.23799 & 0.37422 & 0.52259 & 0.62323 & 1.01429 & 33 \\
\hline lnsize & 0.08326 & 0.27649 & 0.47311 & 0.86411 & 1.12038 & 1.17700 & 1.27435 & 78 \\
\hline $\operatorname{lnbm}$ & 0.06955 & 0.23261 & 0.30736 & 0.53183 & 0.76950 & 0.90269 & 1.19078 & 56 \\
\hline $\mathscr{R}$ & 0.034189 & 0.067414 & 0.089421 & 0.144724 & 0.234217 & 0.300814 & 0.907681 & 4 \\
\hline
\end{tabular}

Critical values of KPSS test of stationarity; using intercept only

(Source: Econometrics Analysis, 2012, William H. Greene)

Cr. Values: 0.739 (at 1\%) $\quad 0.463$ (at 5\%) 0.347 (at $10 \%$ )

(d) KPSS test of stationarity with intercept and linear trend

\begin{tabular}{|c|c|c|c|c|c|c|c|c|}
\hline Series & Min & $\begin{array}{c}25^{\text {th }} \\
\text { smallest }\end{array}$ & $\begin{array}{c}50^{\text {th }} \\
\text { smallest }\end{array}$ & Mid-value & $\begin{array}{c}50^{\text {th }} \\
\text { largest }\end{array}$ & $\begin{array}{c}25^{\text {th }} \\
\text { largest }\end{array}$ & Max & $\begin{array}{c}\text { Percent } \\
\text { accepted unit } \\
\text { root at } 5 \%\end{array}$ \\
\hline \multicolumn{9}{|c|}{ LM Test statistic values for levels; exogenous constant \& linear trend } \\
\hline IVol & 0.05855 & 0.08957 & 0.11114 & 0.15069 & 0.19424 & 0.21883 & 0.35275 & 55 \\
\hline $\mathrm{IVol}^{2}$ & 0.05468 & 0.08332 & 0.09741 & 0.13054 & 0.17524 & 0.20089 & 0.36815 & 41 \\
\hline lnsize & 0.05390 & 0.11269 & 0.13685 & 0.17880 & 0.23604 & 0.25706 & 0.31017 & 69 \\
\hline $\operatorname{lnbm}$ & 0.04701 & 0.09598 & 0.12807 & 0.17328 & 0.21680 & 0.25046 & 0.29758 & 66 \\
\hline $\mathscr{R}$ & 0.02279 & 0.04393 & 0.05296 & 0.06727 & 0.09513 & 0.12789 & 0.21219 & 6 \\
\hline
\end{tabular}

Critical values of KPSS test of stationarity; using intercept \& linear trend

(Source: Econometrics Analysis, 2012, William H. Greene)

Cr. Values: $\quad 0.216$ (at 1\%) $\quad 0.146$ (at 5\%) 0.119 (at $10 \%$ )

We next test the time series of realised excess returns and the explanatory variables for panel cointegration. Westerlund (2007) developed four error-correction based panel cointegration tests, which assume the response variable to possess a deterministic and a stochastic component but allow the explanatory variables to follow random walks. Each test has 'no cointegration' as the null hypothesis. He argues that if the null of no error-correction is rejected, then the null of no cointegration is also rejected. The proposed panel tests exploit the structural rather than the residual dynamics. The tests follow limiting normal distributions and are more powerful than the residual based panel cointegration tests (e.g., Pedroni 2004). Moreover, the Westerlund (2007) tests require only one-step in estimation compared to the residual based tests that need two steps. The general form of the equation for the error correction panel cointegration tests of Westerlund (2007) is, 


$$
d\left(z_{i t}\right)=\delta^{\prime} d_{t}+\alpha\left[z_{i, t-1}-\gamma^{\prime} x_{i, t-1}\right]+\sum_{j=1}^{p_{i}} \zeta_{j} d\left(z_{i, t-1}\right)+\sum_{j=0}^{p_{i}} \eta_{i j}^{\prime} d\left(x_{i, t-1}\right)+e_{i t}
$$

In $\operatorname{Eq}(5), i=1, \ldots N$ and $t=2, \ldots T$ index the cross-sectional units and the time-series, respectively. In equation (5), $z_{i t}$ is the response variable; $x_{i t}$ represents a vector of explanatory variables; $\gamma$ the parameter vector of long-run relationship; the symbol $d(\cdot)$ stands for the first order differencing; $d_{t}=(1, t)^{\prime}$ takes care of the deterministic component in the response variable and $\delta$ ' is its coefficient vector; $\alpha$ is the error-correction parameter, and $p_{i}$ denotes the number of lagged terms required for removing serial correlation. The lagged terms on the first differences of $z$ and $x$ help capture the short-run dynamics in the system, but do not affect $\alpha$ - the error-correction (EC) parameter. The expression in the square brackets is the error-correction term. Thus, the panel cointegration test involves checking whether $\alpha$ is negative and significant.

Equation (5) can be re-parameterized as

$$
d\left(z_{i t}\right)=\delta^{\prime} d_{t}+\alpha z_{i, t-1}+\lambda^{\prime} x_{i, t-1}+\sum_{j=1}^{p_{i}} \zeta_{j} d\left(z_{i, t-1}\right)+\sum_{j=0}^{p_{i}} \eta_{i j}^{\prime} d\left(x_{i, t-1}\right)+e_{i t}
$$

where $\lambda^{\prime}=-\alpha \gamma^{\prime}$. In equation (6), the EC parameter $\alpha$ is unaffected by this rearrangement, which means the least squares estimate of $\alpha$ can be used for performing the tests. Westerlund's tests $G_{\tau}$ and $G_{\alpha}$ are based on the group-mean statistics, while the tests $P_{\tau}$ and $P_{\alpha}$ on the panel statistics; each of the four test statistics follows a normal distribution. The two panel tests are designed to test the alternative that the panel is cointegrated as a whole, while the other two tests assess the alternative that there is at least one cross-section that is cointegrated. The results of the four errorcorrection panel cointegration tests using vector $x$ of explanatory variables as $(\mathrm{lnbm}, I \mathrm{Vol})$ are presented in Table 3. The results of error-correction panel cointegration tests for $x=(I V o l)$ and $\left(\mathrm{lnbm}, \mathrm{IVol}, \mathrm{IVol}^{2}\right)$ are not reported to conserve space, but are available on request. All four tests for each $x$ vector are highly significant, and confirm that there is a panel cointegration between the time series of returns and the explanatory variables.

Table 3

Error-Correction Cointegration Tests: The values in this table are the results of applying the four error-correction cointegration tests of Westerlund (2007) for vector $x=(\operatorname{lnbm}, I \mathrm{Vol})$. (Results from using $x=(\mathrm{IVol})$ and $(\mathrm{lnbm}, I \mathrm{Vol}$, $I V o l^{2}$ ) are not reported to conserve space, but are available on request.) All tests have $p$-values of 0 , and imply that there is a panel cointegration between $\mathscr{R}$ and the vector $x$ of explanatory variables.

\begin{tabular}{lcrcc}
\hline \hline \multirow{2}{*}{ Deterministic component } & Statistics & Value & Z-value & p-value \\
\hline None & $\mathrm{G}_{\tau}$ & -4.9419 & -3.3975 & 0 \\
& $\mathrm{G}_{\alpha}$ & -125.4941 & -21.8846 & 0 \\
& $\mathrm{P}_{\tau}$ & -68.0478 & -50.5050 & 0 \\
& $\mathrm{P}_{\alpha}$ & -111.1051 & -22.1589 & 0 \\
\hline \multirow{2}{*}{ Constant only } & $\mathrm{G}_{\tau}$ & -5.1318 & -3.3629 & 0 \\
& $\mathrm{G}_{\alpha}$ & -133.0625 & -19.7592 & 0 \\
& $\mathrm{P}_{\tau}$ & -69.5290 & -65.6738 & 0 \\
& $\mathrm{P}_{\alpha}$ & -115.3664 & -19.5839 & 0 \\
\hline \multirow{2}{*}{ Constant \& linear trend } & $\mathrm{G}_{\tau}$ & -5.3302 & -3.3321 & 0 \\
& $\mathrm{G}_{\alpha}$ & -140.5096 & -17.3071 & 0 \\
& $\mathrm{P}_{\tau}$ & -71.9373 & -77.2124 & 0 \\
& $\mathrm{P}_{\alpha}$ & -121.3302 & -16.3984 & 0 \\
\hline \hline
\end{tabular}




\subsection{Idiosyncratic risk-return relationship and the panel Error-Correction Model}

A panel error-correction model (ECM) linking the short-run and the long-run dynamics between the expected excess returns and the explanatory variables is specified as

$$
\begin{gathered}
d\left(\boldsymbol{R}_{i t}\right)=\alpha\left[\boldsymbol{R}_{i, t-1}-\gamma^{\prime} x_{i, t-1}\right]+\sum_{j=1}^{p_{i}} \zeta_{j} d\left(\boldsymbol{R}_{i, t-1}\right)+\sum_{j=0}^{p_{i}} \eta_{i j}^{\prime} d\left(x_{i, t-1}\right)+u_{i t} \\
i=1, \ldots, N ; t=2, \ldots, T .
\end{gathered}
$$

In relation (7), $x$ represents a vector of explanatory variables, and the expression in square brackets is the error correction term. The error correction term is $I(0)$ when the variables are cointegrated. The other terms involve $I(0)$ variables since they are expressed in differences. Kumar and Rao (2012) state that an equation involving all $I(0)$ variables can be estimated using any of the classical estimation methods. We use the OLS and the quantile regression methods for estimation. A re-parameterization of equation (7) results in equation (8), which allows one-step estimation.

$$
\begin{gathered}
d\left(\boldsymbol{R}_{i t}\right)=\alpha \boldsymbol{R}_{i, t-1}+\lambda^{\prime} x_{i, t-1}+\sum_{j=1}^{p_{i}} \zeta_{j} d\left(\boldsymbol{R}_{i, t-1}\right)+\sum_{j=0}^{p_{i}} \eta_{i j}^{\prime} d\left(x_{i, t-1}\right)+u_{i t} \\
i=1, \ldots, N ; t=2, \ldots, T .
\end{gathered}
$$

\section{RESULTS}

\subsection{The long-run idiosyncratic risk-return relationship and the panel error-correction models}

Before discussing the main results, we inspect inter-correlations in variables utilized in building various models.

Table 4

Inter-correlations in variables: The reported values are the Pearson correlations. Each coefficient value is based on 24426 paired observations. An absolute value $\geq 0.0128$ is significant at $5 \%$ level and $\geq 0.0165$ at $1 \%$. Significant correlation values are displayed in bold.

\begin{tabular}{lcccccc}
\hline & $\boldsymbol{R}$ & lnsize & $\ln b m$ & $\beta_{M K T}$ & $\beta_{S M B}$ & $\beta_{H M L}$ \\
\hline lnsize & $\mathbf{- 0 . 0 2 4 6 9}$ & & & & & \\
lnbm & $\mathbf{0 . 0 7 1 7 2}$ & $\mathbf{- 0 . 2 5 7 6 9}$ & & & & \\
$\beta_{M K T}$ & 0.00851 & $\mathbf{0 . 0 1 8 9 6}$ & -0.00255 & & & \\
$\beta_{S M B}$ & 0.01085 & $\mathbf{- 0 . 2 9 9 7 2}$ & $\mathbf{0 . 0 2 4 7 7}$ & $\mathbf{0 . 3 8 3 9 6}$ & & \\
$\beta_{H M L}$ & $\mathbf{0 . 0 3 4 7 1}$ & $\mathbf{- 0 . 0 3 1 6 1}$ & $\mathbf{0 . 2 2 9 7 9}$ & $\mathbf{0 . 1 7 4 1 8}$ & -0.00848 & \\
$I V o l$ & -0.00160 & $\mathbf{- 0 . 5 6 8 5 2}$ & $\mathbf{0 . 1 6 0 0 7}$ & $\mathbf{0 . 1 3 5 4 1}$ & $\mathbf{0 . 3 8 8 4 5}$ & $\mathbf{0 . 0 2 9 8 6}$ \\
\hline \hline
\end{tabular}

Table 4 reports Pearson's correlation coefficients, $r$. Each coefficient is based on 24426 paired observations, and, with the exception of a few, are highly significant (an absolute value $\geq 0.0128$ is significant at $5 \%$, and an absolute value $\geq 0.0165$ at $1 \%$ ). For example, the estimated values of coefficients $\beta_{M K T}, \beta_{S M B}$, and $\beta_{H M L}$, obtained in the first stage of the Fama-MacBeth method from 
equation (1) that are traditionally used as explanatory variables in equation (2) for the second stage estimation, are highly correlated with lnsize and $\operatorname{lnbm}$. Of the others, Insize has highly significant negative correlation with $\operatorname{lnbm}(r=-0.2578)$ and $\mathrm{IVol}(r=-0.5685)$, meaning smaller stocks possess higher $\mathrm{IVol}$ and $\mathrm{lnbm}$ ratios. The use of highly correlated explanatory variables is likely to create a collinearity problem. Moreover, Figure 1 shows that $I V o l$ has a non-linear declining relationship with Insize. Nonetheless, for benchmarking we start by fitting and reporting the long-run relationship model based on equation (2) utilizing all explanatory variables.

\section{Figure 1}

Idiosyncratic volatility and Insize relationship in the cross-section: The scatter plot shows average idiosyncratic volatility in an individual stock against its average lnsize over the 10-year study period.

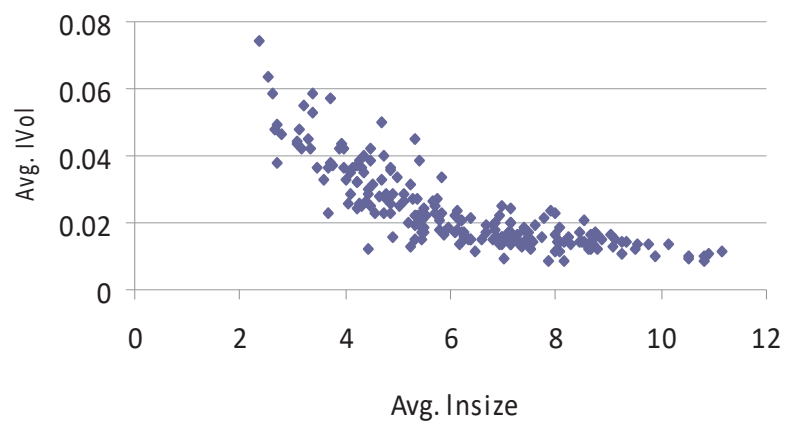

\subsubsection{The OLS estimation evidence}

Model 1 in Table 5 part (a) reports the OLS estimation of model using all explanatory variables. The adjusted $R^{2}$ (Adj- $R^{2}$ ) value of this model is only 0.06741 , implying that the fitted model is not able to capture the relationship dynamics well, but it is at least comparable to the reported values of the best fitting models in Ang et al. (2009, Tables 2 and 8) for the US data. The best fitting model in Hur (2010, Table 7, Panel 8) has $\mathrm{R}^{2}$ value of 0.0091 for the Australian data. Huang et al. (2010, Table 1, Models 2 and 3), do not report $R^{2}$ or the Adj- $R^{2}$ values, so one does not know how well their models performed.

Table 5

(a) Ordinary least squares estimation of Long-run idiosyncratic risk-return relationship models: The reported values are the Fama-MacBeth (1973) pooled estimates and the associated $t$-statistic values (in parentheses) from fitting Models $1-4$. The response variable is $\mathscr{R}$, and the predictors are listed in the first column along with the average coefficient of determination and the average adjusted coefficient of determination values.

\begin{tabular}{|c|c|c|c|c|}
\hline & Model 1 & Model 2 & Model 3 & Model 4 \\
\hline intercept & $7.64 \mathrm{E}-05 \quad(0.1917)$ & 0.00073 (1.7254) & $0.00033(1.5495)$ & 0.00059 (2.6171) \\
\hline lnsize & $1.92 \mathrm{E}-05 \quad(0.5184)$ & $-1.98 \mathrm{E}-05 \quad(-0.5257)$ & & \\
\hline $\operatorname{lnbm}$ & $0.00050(6.3434)$ & $0.00050 \quad(6.4527)$ & 0.00055 (6.7143) & $0.00054 \quad(\mathbf{6 . 6 7 7 1})$ \\
\hline$\beta_{M K T}$ & $-1.96 \mathrm{E}-05 \quad(-0.2440)$ & $-1.36 \mathrm{E}-05 \quad(-0.1780)$ & & \\
\hline$\beta_{S M B}$ & $-0.00020(-0.1212)$ & $-0.00141 \quad(-0.7839)$ & & \\
\hline$\beta_{H M L}$ & $0.00325(1.9737)$ & $0.00176(1.0286)$ & & \\
\hline IVol & $0.00167(0.2517)$ & $-0.02994(-2.0405)$ & $-0.00214(-0.3229)$ & $-0.02378(-1.5881)$ \\
\hline $\mathrm{IVol}^{2}$ & & $0.38300(2.0156)$ & & 0.30473 (1.7228) \\
\hline $\mathrm{R}^{2}$ & 0.09458 & 0.10974 & 0.04803 & 0.06471 \\
\hline Adj- $R^{2}$ & 0.06741 & 0.07842 & 0.03869 & 0.05089 \\
\hline
\end{tabular}


(b) Ordinary least squares estimation of Panel Error-Correction Models: This table reports ordinary least squares estimation of two panel error-correction models ECM 1 and ECM 2 encompassing explanatory variables $\ln b m$ and $I V o l$, and $l n b m, I V o l$ and $I V o l^{2}$, respectively. The response variable is $d(R)$. The first column displays variables in the model and the implied long-run relationship parameters estimates $\gamma_{k}^{*}, \mathrm{k}=0,1,2,3$, (denoting the intercept and the coefficients of $l n b m, I V o l$ and $I V o l^{2}$, respectively) obtained using the relation, $\lambda^{\prime}=-\alpha \gamma^{\prime}$. The average values of coefficient of determination and adjusted coefficient of determination for the models are also reported. Notation $Z(-1)$ stands for 'lag one' value of variable $Z$, and $d(Z)$, the first differences. The reported values are the FamaMacBeth (1973) pooled estimates and in parentheses, the associated $t$-statistic values. Significant coefficient estimates of important variables are displayed in bold.

\begin{tabular}{|c|c|c|}
\hline & ECM 1 & ECM 2 \\
\hline Intercept & $0.00043(3.5756)$ & $0.00046(3.5211)$ \\
\hline$\gamma_{0}^{*}$ & $0.00082(3.5921)$ & $0.00086(3.5516)$ \\
\hline $\mathscr{R}(-1)$ & $-0.62519(-52.5573)$ & $-0.62692(-52.4746)$ \\
\hline $\operatorname{lnbm}(-1)$ & $0.00050 \quad(5.6542)$ & $0.00052 \quad(5.8682)$ \\
\hline$\gamma_{1}^{*}$ & $0.00086(5.6283)$ & $0.00090(5.8773)$ \\
\hline $\operatorname{IVol}(-1)$ & $-0.00533(-1.1427)$ & $-0.00476(-1.0150)$ \\
\hline$\gamma_{2}^{*}$ & $-0.01209(-1.4352)$ & $-0.01151 \quad(-1.3512)$ \\
\hline $\operatorname{IVol}^{2}(-1)$ & & $-0.03181 \quad(-0.5781)$ \\
\hline$\gamma_{3}^{*}$ & & $-0.04080 \quad(-0.4754)$ \\
\hline$d(\mathscr{R}(-1))$ & $-0.18915(-20.1382)$ & $-0.18918(-19.8554)$ \\
\hline$d(\ln b m)$ & $0.00066(9.5844)$ & $0.00065(9.4901)$ \\
\hline$d(\ln b m(-1))$ & 0.00006 (1.0382) & $0.00005(0.7540)$ \\
\hline$d(I V o l)$ & $-0.00327(-0.7517)$ & $-0.00292(-0.6697)$ \\
\hline$d(\operatorname{IVol}(-1))$ & 0.00393 (1.2012) & 0.00367 (1.1091) \\
\hline$d\left(I V o l^{2}\right)$ & & $-0.01444(-0.4151)$ \\
\hline$d\left(\operatorname{IVol}^{2}(-1)\right)$ & & $0.05634(1.2247)$ \\
\hline $\mathrm{R}^{2}$ & 0.44509 & 0.45335 \\
\hline $\operatorname{Adj}-R^{2}$ & 0.42267 & 0.42251 \\
\hline
\end{tabular}

The weakest correlation value (-0.0016) in Table 4 is the correlation between $I V o l$ and the realized future returns, which is negative and not significant. This near zero correlation value could mean a lack of linearity in the relationship. Using a quadratic term in $\mathrm{IVol}$ along with all other explanatory variables employed in Model 1 of Table 5 part (a) is reported as Model 2. This produces a slight improvement in the Adj- $\mathrm{R}^{2}$ value. Moreover, this makes the coefficient of IVol negative and significant, while producing the coefficient of $\mathrm{IVol}^{2}$ as positive and significant. Viewing the coefficients of $\mathrm{IVol}$ and $\mathrm{IVOl}^{2}$ across Models 2, 3 and 4 in Table 5, and observing the $\mathrm{IVO}$ and lnsize relationship pattern in Figure 1, one wonders whether the observed quadratic effect of $\mathrm{IVol}$ a consequence of the non-linear relationship between $\mathrm{IVol}$ and lnsize.

It is well documented in the literature that firms with smaller market capitalization yield higher returns (Banz, 1981; Beedles et al., 1988; Fama and French, 1992; O'Brien et al., 2012 and references therein) and carry higher idiosyncratic risk (e.g. Ang et al., 2006, 2009; Hur, 2010; Jiang et al., 2006; Lu-Andrews and Glascock, 2014). Thus, it follows by the law of association that high idiosyncratic risk may lead to high returns. To avoid making this presumption and a collinearity problem due to inter-correlations, and especially because of the non-linear relationship between $\mathrm{IVol}$ and lnsize (Figure 1) impacting the returns behaviour endogenously, we 
drop variable lnsize from the model. We find the OLS estimates of the slope coefficients of $\beta_{M K T \text {, }}$ $\beta_{S M B}$ and $\beta_{H M L}$ are not significant, so drop them as predictors from further models. As the interest is to find out if $\mathrm{IVol}$ has any explanatory power, and the form of its relationship with the returns of the next period, the only regressors we consider are $l n b m$, IVol and $\mathrm{IVol}^{2}$. Model 3 in Table 5 part (a) utilizes $l n b m$ and $I V o l$ as the regressors, while Model 4 employs $l n b m, I V o l$ and $\mathrm{IVol}^{2}$. Models 3 and 4 will be referred to as the reduced variables linear $I V o l$ and the quadratic $I V o l$ models, respectively. In Models 3 and 4, $\operatorname{lnbm}$ has positive significant marginal effect on returns, and agrees with the reported findings in the literature (e.g., Ang et al., 2009; Fama and French, 1992; Fu, 2009, for the US markets, and O'Brien et al., 2012; Hur, 2010, for the Australian market). The coefficients of $\mathrm{IVol}$ in Models 3 and 4 are negative but not significant; Model 4 shows $\mathrm{IVol}^{2}$ has a nonsignificant positive impact on expected returns.

Having identified a panel cointegration between the time series of returns and the series of $l n b m$ and $\mathrm{IVol}$, we next estimate models within the panel error-correction framework using explanatory variables employed in Models 3 and 4 in Table 5, part (a). These model fittings are reported as ECM 1 and ECM 2 in Table 5 part (b). Notation $Z(-1)$ denotes 'lag one' value of variable $Z$. Coefficients $\gamma_{k}{ }^{*}, k=0,1,2,3$, are the implied parameters of long-run relationship derived using $\lambda^{\prime}=-\alpha \gamma^{\prime \prime}$. Specifically, $\gamma_{k}{ }^{*}, k=0,1,2,3$, represent the implied estimates of intercept and slope coefficients of $\operatorname{lnbm}, \mathrm{IVol}$, and $\mathrm{IVol}^{2}$, respectively. The reported coefficient estimates and the $t$-statistic values are obtained using the Fama-MacBeth pooling method. The improvement in Adj- $\mathrm{R}^{2}$ value from using the panel ECMs is huge; the Adj- $\mathrm{R}^{2}$ value of $4 \%$ for Model 3 jumps to $42 \%$ and $5 \%$ for Model 4 to $42.25 \%$. This additional power comes from the error-correction structure. Moreover, $\alpha$ - the average coefficient of $\mathscr{R}(-1)$, which is also the error-correction parameter, is negative $(-0.625)$ and highly significant ${ }^{9}$. This implies that each 20 -day observation period, the response $\mathcal{R}$ reacts to restore the long-run equilibrium at a speed of $62.5 \%$. This errorcorrection mechanism, which at the mean level is dominated by $\operatorname{lnbm}$ ratios, is possibly due to investors overvaluing or undervaluing stocks while seeking opportunities to buy or sell stocks. The long-run $\mathrm{IVol}$ risk-return relationship at the mean level is still negative but not significant.

The coefficients of $d(\operatorname{lnbm})$ and $d(\Re(-1))$ are highly significant in both ECM 1 and ECM 2 and suggest that the short-run adjustments in $\mathscr{R}$ in a period are linked to changes in $\ln b m$ and changes in returns in the previous period. While the short-run adjustments in $\mathscr{R}$ (i.e., $d(\mathscr{R})$ ) have positive significant dependence on $d(\operatorname{lnbm})$, the relationship between $d(\mathscr{R})$ and $d(\mathscr{R}(-1))$ is negative and significant. This negative relation may be interpreted as the return-reversal process in the shortrun returns ${ }^{10}$. Thus, the use of a panel ECM is able to capture and explain a finer dynamics in realized future excess stock returns.

The signs and significance of the implied long-run relationship parameters are the same as the ones reported for Models 3 and 4 in Table 5, part (a). The implied long-run relationship intercept, $\gamma_{0}{ }^{*}$, is positive and significant in both ECM 1 and ECM 2; the implied long-run marginal effect $\gamma_{1}{ }^{*}$ of $\operatorname{lnbm}$ is also positive and significant. In ECM 1 and ECM 2, the implicated long-run marginal effect $\gamma_{2}{ }^{*}$ of $\mathrm{IVO}$ at the mean level is negative but not significant. As the coefficients of $d(I V o l)$ estimated using OLS are not significant in ECM 1 and ECM 2, there seems to be no shortrun dependence of $\mathscr{R}$, at least on average, on changes in $I V o l$. However, the quantile regression estimation (see next section) support the short-run dependence of $R$ on changes in $I V o l$.

\subsubsection{The quantile regression estimation evidence}

The relationship in the tails of the conditional returns distribution is of particular interest to investors as it signifies large gains and losses. Moreover, the distribution of returns may not be symmetric, and therefore, the OLS estimation results, which apply at the mean level, may not

We also observed $\alpha_{i}$ to be highly significant in each panel.

10 CGW (1993), Fu (2009), Huang et al. (2010), Jegadeesh (1990), Jegadeesh and Titman (1993) and Lehmann (1990) report observing returnreversal process in the levels of returns for the US data. 
serve well. Barnes and Hughes (2002) remark that 'the ordinary least squares based conclusions can be very narrowly focussed and may not reflect the true form of the relationship........ A fortunate by-product of the quantile regression approach is that it alleviates the statistical problems like errors-in-variables, omitted variables bias, sensitivity to outliers and non-normal errors distributions which affect the empirical investigations in asset pricing models'. Also, if the OLS results approximately match the quantile regression based estimates around the median level, it is a confirmation of the observed pattern. The use of quantile regression is not new in empirical economics, finance and many business areas. Barnes \& Hughes (2002) use quantile regression for examining the beta risk and the returns relationship in one-factor capital asset pricing model; Engle \& Manganelli (2004) apply it to study the problem of Value at Risk; Wan (2008) estimates idiosyncratic volatility using this method. Kuan et al. (2012) employ the quantile regression to study the relationship between excess control rights and cash holdings. Some further applications and details of the methodology can be found in Bassett and Chen (2001), Buchinsky (1997, 1998), Koenker and Bassett (1978) and Koenker and Hallock (2001). We now estimate models reported in Table 5 parts (a) and (b) using quantile regression. However, to conserve space we report only Models 2, 4 and panel ECM 1. While Model 2 involves all variables, Model 4 and ECM 1 have reduced number of explanatory variables.

Table 6

Nonlinearity in long-run idiosyncratic risk-returns relationship models

(a) The fitted model is $\boldsymbol{R}=f n$ [intercept, lnsize, $\left.\ln b m, \beta_{M K T}, \beta_{S M B}, \beta_{H M L}, I V o l, I V o l^{2}\right]$. Notation $f n[$.] stands for 'function of'. The table reports the Fama-MacBeth (1973) pooled estimates of coefficients of the fitted model obtained using the quantile regression and the OLS methods. The associated $t$-statistic values are in parentheses. The OLS estimates are the Model 2 values replicated from Table 5 part (a) to facilitate comparison. Significant coefficient estimates are displayed in bold.

\begin{tabular}{|c|c|c|c|c|c|c|c|c|c|c|}
\hline \multirow[b]{2}{*}{ Variable } & \multicolumn{8}{|c|}{ Quantile } & \multirow[b]{2}{*}{0.9} & \multirow[b]{2}{*}{ OLS } \\
\hline & 0.1 & 0.2 & 0.3 & 0.4 & 0.5 & 0.6 & 0.7 & 0.8 & & \\
\hline intercept & $\begin{array}{l}-0.0037 \\
(-6.420)\end{array}$ & $\begin{array}{l}-0.0019 \\
(-4.863)\end{array}$ & $\begin{array}{l}-0.0012 \\
(-3.249)\end{array}$ & $\begin{array}{l}-0.0005 \\
(-1.524)\end{array}$ & $\begin{array}{c}1.1 \mathrm{E}-04 \\
(0.351)\end{array}$ & $\begin{array}{l}0.0009 \\
(2.434)\end{array}$ & $\begin{array}{l}0.0015 \\
(3.959)\end{array}$ & $\begin{array}{c}\mathbf{0 . 0 0 3 0} \\
(7.058)\end{array}$ & $\begin{array}{l}0.0054 \\
(8.658)\end{array}$ & $\begin{array}{l}0.0007 \\
(1.725)\end{array}$ \\
\hline Insize & $\begin{array}{c}3.0 \mathrm{E}-04 \\
(6.183)\end{array}$ & $\begin{array}{c}1.9 E-04 \\
(4.936)\end{array}$ & $\begin{array}{c}1.3 E-04 \\
(3.812)\end{array}$ & $\begin{array}{c}8.7 \mathrm{E}-05 \\
(2.866)\end{array}$ & $\begin{array}{c}4.6 \mathrm{E}-05 \\
(1.572)\end{array}$ & $\begin{array}{c}-3.0 \mathrm{E}-05 \\
(-0.902)\end{array}$ & $\begin{array}{c}-8.5 E-05 \\
(-2.327)\end{array}$ & $\begin{array}{c}-2.3 E-04 \\
(-5.936)\end{array}$ & $\begin{array}{c}-4.3 E-04 \\
(-7.880)\end{array}$ & $\begin{array}{c}-2.0 \mathrm{E}-05 \\
(-0.526)\end{array}$ \\
\hline $\operatorname{lnbm}$ & $\begin{array}{c}6.4 \mathrm{E}-04 \\
(5.865)\end{array}$ & $\begin{array}{c}5.1 \mathrm{E}-04 \\
(5.840)\end{array}$ & $\begin{array}{c}3.7 E-04 \\
(4.491)\end{array}$ & $\begin{array}{c}3.1 \mathrm{E}-04 \\
(4.553)\end{array}$ & $\begin{array}{c}2.4 \mathrm{E}-04 \\
(3.988)\end{array}$ & $\begin{array}{c}1.9 \mathrm{E}-04 \\
(3.150)\end{array}$ & $\begin{array}{c}1.9 E-04 \\
(2.829)\end{array}$ & $\begin{array}{c}1.4 \mathrm{E}-04 \\
(1.860)\end{array}$ & $\begin{array}{c}3.6 \mathrm{E}-05 \\
(0.401)\end{array}$ & $\begin{array}{c}5.0 \mathrm{E}-04 \\
(6.453)\end{array}$ \\
\hline$\beta_{M K T}$ & $\begin{array}{c}-2.3 \mathrm{E}-04 \\
(-1.744)\end{array}$ & $\begin{array}{c}-1.1 \mathrm{E}-04 \\
(-1.263)\end{array}$ & $\begin{array}{c}-1.6 \mathrm{E}-04 \\
(-1.624)\end{array}$ & $\begin{array}{c}-6.3 \mathrm{E}-05 \\
(-0.773)\end{array}$ & $\begin{array}{c}-5.1 \mathrm{E}-05 \\
(-0.644)\end{array}$ & $\begin{array}{c}8.6 \mathrm{E}-05 \\
(1.201)\end{array}$ & $\begin{array}{c}1.2 \mathrm{E}-04 \\
(1.534)\end{array}$ & $\begin{array}{c}2.2 \mathrm{E}-04 \\
(2.606)\end{array}$ & $\begin{array}{c}3.5 E-04 \\
(3.416)\end{array}$ & $\begin{array}{r}-1.4 \mathrm{E}-05 \\
(-0.178)\end{array}$ \\
\hline$\beta_{S M B}$ & $\begin{array}{l}-0.0020 \\
(-0.772)\end{array}$ & $\begin{array}{l}-0.0042 \\
(-2.092)\end{array}$ & $\begin{array}{l}-0.0019 \\
(-1.149)\end{array}$ & $\begin{array}{l}-0.0026 \\
(-1.636)\end{array}$ & $\begin{array}{l}-0.0014 \\
(-0.957)\end{array}$ & $\begin{array}{l}-0.0018 \\
(-1.375)\end{array}$ & $\begin{array}{l}-0.0011 \\
(-0.708)\end{array}$ & $\begin{array}{l}-0.0017 \\
(-0.916)\end{array}$ & $\begin{array}{l}-0.0007 \\
(-0.253)\end{array}$ & $\begin{array}{l}-0.0014 \\
(-0.784)\end{array}$ \\
\hline$\beta_{H M L}$ & $\begin{array}{l}0.0025 \\
(1.156)\end{array}$ & $\begin{array}{l}0.0014 \\
(0.778)\end{array}$ & $\begin{array}{l}0.0033 \\
(2.022)\end{array}$ & $\begin{array}{l}0.0028 \\
(1.855)\end{array}$ & $\begin{array}{l}0.0026 \\
(1.530)\end{array}$ & $\begin{array}{l}0.0019 \\
(1.073)\end{array}$ & $\begin{array}{l}0.0017 \\
(0.890)\end{array}$ & $\begin{array}{l}0.0007 \\
(0.344)\end{array}$ & $\begin{array}{l}-0.0012 \\
(-0.482)\end{array}$ & $\begin{array}{c}0.0018 \\
(1.029)\end{array}$ \\
\hline IVol & $\begin{array}{c}-0.1999 \\
(-10.625)\end{array}$ & $\begin{array}{c}-0.1460 \\
(-10.165)\end{array}$ & $\begin{array}{l}-0.0975 \\
(-7.560)\end{array}$ & $\begin{array}{l}-0.0636 \\
(-5.312)\end{array}$ & $\begin{array}{l}-0.0255 \\
(-2.229)\end{array}$ & $\begin{array}{l}0.0128 \\
(1.183)\end{array}$ & $\begin{array}{l}0.0533 \\
(4.349)\end{array}$ & $\begin{array}{l}0.1031 \\
(7.089)\end{array}$ & $\begin{array}{l}0.1549 \\
(6.974)\end{array}$ & $\begin{array}{l}-0.0299 \\
(-2.041)\end{array}$ \\
\hline $\mathrm{IVol}^{2}$ & $\begin{array}{l}1.3483 \\
(5.929)\end{array}$ & $\begin{array}{l}0.9438 \\
(4.907)\end{array}$ & $\begin{array}{l}0.6023 \\
(3.479)\end{array}$ & $\begin{array}{l}0.4244 \\
(2.624)\end{array}$ & $\begin{array}{c}0.1793 \\
(1.147)\end{array}$ & $\begin{array}{l}-0.0799 \\
(-0.539)\end{array}$ & $\begin{array}{l}-0.2290 \\
(-1.331)\end{array}$ & $\begin{array}{l}-0.5747 \\
(-2.693)\end{array}$ & $\begin{array}{l}-0.5362 \\
(-1.981)\end{array}$ & $\begin{array}{l}0.3830 \\
(2.016)\end{array}$ \\
\hline $\mathrm{R}^{2}$ & 0.1626 & 0.1137 & 0.0838 & 0.0647 & 0.0571 & 0.0589 & 0.0708 & 0.0994 & 0.1645 & 0.1097 \\
\hline Adj-R ${ }^{2}$ & 0.1332 & 0.0825 & 0.0515 & 0.0318 & 0.0239 & 0.0258 & 0.0381 & 0.0677 & 0.1351 & 0.0784 \\
\hline
\end{tabular}


(b) The quantile and the OLS regressions of nonlinear model in IVol using reduced number of predictors. The reported values are obtained using the Fama-MacBeth (1973) pooling method; the associated t-statistic values are in parentheses.

\begin{tabular}{|c|c|c|c|c|c|c|c|c|c|c|}
\hline \multicolumn{11}{|c|}{ Quantile } \\
\hline Variable & 0.1 & 0.2 & 0.3 & 0.4 & 0.5 & 0.6 & 0.7 & 0.8 & 0.9 & OLS \\
\hline intercept & $\begin{array}{c}-7.3 E-04 \\
(-2.333)\end{array}$ & $\begin{array}{c}-2.2 \mathrm{E}-04 \\
(-0.944)\end{array}$ & $\begin{array}{c}4.7 \mathrm{E}-05 \\
(0.211)\end{array}$ & $\begin{array}{c}2.6 \mathrm{E}-04 \\
(1.380)\end{array}$ & $\begin{array}{c}5.0 \mathrm{E}-04 \\
(2.939)\end{array}$ & $\begin{array}{c}6.3 \mathrm{E}-04 \\
(3.606)\end{array}$ & $\begin{array}{r}8.1 \mathrm{E}-04 \\
(4.174)\end{array}$ & $\begin{array}{l}1.0 \mathrm{E}-03 \\
(4.669)\end{array}$ & $\begin{array}{c}1.5 \mathrm{E}-03 \\
(5.495)\end{array}$ & $\begin{array}{l}5.9 \mathrm{E}-04 \\
(2.617)\end{array}$ \\
\hline $\operatorname{lnbm}$ & $\begin{array}{c}5.6 \mathrm{E}-04 \\
(5.155)\end{array}$ & $\begin{array}{c}3.8 \mathrm{E}-04 \\
(4.954)\end{array}$ & $\begin{array}{c}3.5 \mathrm{E}-04 \\
(4.838)\end{array}$ & $\begin{array}{c}3.1 \mathrm{E}-04 \\
(4.325)\end{array}$ & $\begin{array}{c}2.7 \mathrm{E}-04 \\
(4.375)\end{array}$ & $\begin{array}{c}2.5 \mathrm{E}-04 \\
(3.901)\end{array}$ & $\begin{array}{c}2.2 \mathrm{E}-04 \\
(3.071)\end{array}$ & $\begin{array}{c}2.3 \mathrm{E}-04 \\
(2.963)\end{array}$ & $\begin{array}{c}3.0 \mathrm{E}-04 \\
(3.067)\end{array}$ & $\begin{array}{l}5.4 \mathrm{E}-04 \\
(6.677)\end{array}$ \\
\hline IVol & $\begin{array}{c}-0.2637 \\
(-14.691)\end{array}$ & $\begin{array}{c}-0.1800 \\
(-12.340)\end{array}$ & $\begin{array}{l}-0.1213 \\
(-9.076)\end{array}$ & $\begin{array}{l}-0.0676 \\
(-5.819)\end{array}$ & $\begin{array}{l}-0.0248 \\
(-2.121)\end{array}$ & $\begin{array}{l}0.0235 \\
(1.912)\end{array}$ & $\begin{array}{l}0.0722 \\
(5.159)\end{array}$ & $\begin{array}{l}0.1423 \\
(8.800)\end{array}$ & $\begin{array}{c}0.2442 \\
(11.437)\end{array}$ & $\begin{array}{l}-0.0238 \\
(-1.588)\end{array}$ \\
\hline $\mathrm{IVol}^{2}$ & $\begin{array}{l}1.6200 \\
(7.424)\end{array}$ & $\begin{array}{l}1.0460 \\
(5.942)\end{array}$ & $\begin{array}{l}0.6913 \\
(4.149)\end{array}$ & $\begin{array}{l}0.2897 \\
(2.008)\end{array}$ & $\begin{array}{l}0.0476 \\
(0.336)\end{array}$ & $\begin{array}{l}-0.1921 \\
(-1.349)\end{array}$ & $\begin{array}{l}-0.3421 \\
(-1.970)\end{array}$ & $\begin{array}{l}-0.6844 \\
(-3.380)\end{array}$ & $\begin{array}{l}-1.0066 \\
(-2.917)\end{array}$ & $\begin{array}{l}0.3047 \\
(1.723)\end{array}$ \\
\hline $\mathrm{R}^{2}$ & 0.1200 & 0.0801 & 0.0542 & 0.0389 & 0.0321 & 0.0337 & 0.0435 & 0.0661 & 0.1179 & 0.0647 \\
\hline $\operatorname{Adj}-R^{2}$ & 0.1070 & 0.0665 & 0.0403 & 0.0247 & 0.0178 & 0.0194 & 0.0293 & 0.0523 & 0.1049 & 0.0509 \\
\hline
\end{tabular}

Table 6 parts (a) and (b) display quantile regression estimation of Table 5 part (a) Models 2 and 4, respectively, and provide benchmark for assessing panel ECM results. The reported values are the pooled estimated coefficients and the test-statistic values obtained by applying equations (3) and (4). The last column in Table 6, labelled OLS, reproduces information from Table 5 to facilitate comparison. It can be observed from the quantile regression estimation of intercept that large negative (positive) abnormal returns are associated with the lower (upper) quantiles of the returns distribution. The $t$-statistic values for Insize are highly significant at the extreme quantiles, and the marginal effect of lnsize on expected excess returns decreases from being positive at the lower quantiles to negative at the upper quantiles.

The quantile regression estimates of slope coefficient of $\mathrm{lnbm}$ are positive and significant at all quantiles with the exception of the $80^{\text {th }}$ and the $90^{\text {th }}$ quantiles where they are positive but not significant. In the reduced variables model (Table 6 part (b)), lnbm shows positive and significant effect at all quantiles, and implies the dominance of $\ln \mathrm{bm}$ in explaining expected excess returns. The quantile regression estimates of the slope coefficients $\beta_{M K T} \beta_{S M B}$ and $\beta_{H M L}$ are significant only at an occasional quantile suggesting that they do not have a significant effect over and above the effect of lnsize, lnbm, and IVol, and are not included in the reduced variables model in Table 6 part (b).

It is clear from Table 6 parts (a) and (b) that the marginal linear effect of idiosyncratic risk is highly significant in the tails of the conditional distribution of excess returns; the relationship form is not impacted by the removal of lnsize as a predictor. The relationship impact changes from being negative and significant at the lower quantiles to positive and significant at the upper quantiles, but is not significant around the median. The slope coefficients of $I V O l^{2}$ are positive (negative) and significant at the lower (upper) quantiles. The significant $t$-statistic values of the marginal effects of $\mathrm{IVol}^{2}$ at many lower and upper quantiles indicate the presence of a quadratic relation between the $\mathrm{IVol}$ and the future excess returns, a finding reported in Nath and Brooks (2015). The reduced variables model in Table 6 part (b) mirrors this pattern; the overall idiosyncratic riskreturn relationship form is not impacted by the use of reduced number of variables. Comparing the OLS and the quantile regression based IVol slope coefficient estimates in the full model (Table 6 part (a)) and the reduced variables model (Table 6 part (b)), it follows that the relationship pattern around the median ${ }^{11}$ is similar to the pattern at the average level captured by the OLS estimation, but the quantile regression provides a much richer dynamics of the relationship.

11 The return distribution is possibly not symmetric (Nath and Brooks (2015), therefore, the $50^{\text {th }}$ quantile may not reflect the average level. 
Table 7 reports quantile regression estimation of panel ECM 1 reported in Table 5 part (b). For conserving space, results for panel ECM 2 are not reported, but are available on request. We can make the following observations from this table.

Table 7

Estimation of Panel Error-Correction Models using quantile regression: This table reports fitting of panel ECM encompassing explanatory variables $\mathrm{lnbm}$ and $\mathrm{IVol}$, an equivalent of ECM 1 in Table 5 part (b), which is replicated in the last column to facilitate comparison. The response variable is $d(\mathscr{R})$. The first column displays the explanatory variables in the model and the implied parameters $\gamma_{k}{ }^{*}, \mathrm{k}=0,1,2$, (denoting the intercept and the coefficients of lnbm and $\mathrm{IVol}$, respectively) obtained using relation, $\lambda^{\prime}=-\alpha \gamma^{\prime}$. Notation $Z(-1)$ stands for 'lag one' value of variable $Z$, and $d(Z)$, the first differences. The reported values are the pooled estimates and the associated $t$-statistic values (in parentheses) obtained using Fama-MacBeth (1973) method. Significant coefficient estimates of important variables are displayed in bold.

\begin{tabular}{|c|c|c|c|c|c|c|c|c|c|c|}
\hline \multicolumn{11}{|c|}{ Quantile } \\
\hline & 0.1 & 0.2 & 0.3 & 0.4 & 0.5 & 0.6 & 0.7 & 0.8 & 0.9 & OLS \\
\hline Intercept & $\begin{array}{l}-0.0016 \\
(-9.357)\end{array}$ & $\begin{array}{l}-6.3 E-04 \\
(-5.448)\end{array}$ & $\begin{array}{l}-1.8 \mathrm{E}-04 \\
(-2.055)\end{array}$ & $\begin{array}{l}1.4 \mathrm{E}-04 \\
(1.639)\end{array}$ & $\begin{array}{l}3.9 \mathrm{E}-04 \\
(5.139)\end{array}$ & $\begin{array}{l}7.6 \mathrm{E}-04 \\
(9.648)\end{array}$ & $\begin{array}{l}0.0011 \\
(11.818)\end{array}$ & $\begin{array}{l}0.0013 \\
(11.908)\end{array}$ & $\begin{array}{l}0.0020 \\
(12.090)\end{array}$ & $\begin{array}{l}4.3 \mathrm{E}-04 \\
(3.576)\end{array}$ \\
\hline$\gamma_{0}^{*}$ & $\begin{array}{l}-0.0027 \\
(-8.865)\end{array}$ & $\begin{array}{l}-0.0010 \\
(-4.968)\end{array}$ & $\begin{array}{l}-3.0 E-04 \\
(-2.122)\end{array}$ & $\begin{array}{l}1.5 \mathrm{E}-04 \\
(1.250)\end{array}$ & $\begin{array}{l}5.7 E-04 \\
(5.008)\end{array}$ & $\begin{array}{l}0.0011 \\
(9.528)\end{array}$ & $\begin{array}{l}0.0015 \\
(11.487)\end{array}$ & $\begin{array}{l}0.0019 \\
(11.026)\end{array}$ & $\begin{array}{l}0.0030 \\
(11.296)\end{array}$ & $\begin{array}{l}\text { 8.2E-04 } \\
(3.592)\end{array}$ \\
\hline $\mathscr{R}(-1)$ & $\begin{array}{l}-0.5996 \\
(-44.143)\end{array}$ & $\begin{array}{l}-0.6509 \\
(-59.412)\end{array}$ & $\begin{array}{l}-0.6769 \\
(-65.544)\end{array}$ & $\begin{array}{l}-0.6868 \\
(-71.867)\end{array}$ & $\begin{array}{l}-0.7032 \\
(-76.835)\end{array}$ & $\begin{array}{l}-0.7125 \\
(-87.320)\end{array}$ & $\begin{array}{l}-0.7068 \\
(-77.681)\end{array}$ & $\begin{array}{l}-0.7026 \\
(-62.441)\end{array}$ & $\begin{array}{l}-0.6931 \\
(-45.697)\end{array}$ & $\begin{array}{l}-0.6252 \\
(-52.557)\end{array}$ \\
\hline $\ln b m(-1)$ & $\begin{array}{l}6.8 \mathrm{E}-04 \\
(5.112)\end{array}$ & $\begin{array}{l}5.1 \mathrm{E}-04 \\
(5.418)\end{array}$ & $\begin{array}{l}4.2 \mathrm{E}-04 \\
(5.527)\end{array}$ & $\begin{array}{l}4.2 \mathrm{E}-04 \\
(6.511)\end{array}$ & $\begin{array}{l}2.9 \mathrm{E}-04 \\
(4.387)\end{array}$ & $\begin{array}{l}1.9 \mathrm{E}-04 \\
(2.774)\end{array}$ & $\begin{array}{l}1.7 \mathrm{E}-04 \\
(2.293)\end{array}$ & $\begin{array}{l}7.3 \mathrm{E}-05 \\
(0.830)\end{array}$ & $\begin{array}{l}-1.1 \mathrm{E}-04 \\
(-0.867)\end{array}$ & $\begin{array}{l}5.0 \mathrm{E}-04 \\
(5.654)\end{array}$ \\
\hline$\gamma_{1}^{*}$ & $\begin{array}{l}0.0012 \\
(4.705)\end{array}$ & $\begin{array}{l}\text { 7.8E-04 } \\
(4.943)\end{array}$ & $\begin{array}{l}\text { 6.2E-04 } \\
(5.431)\end{array}$ & $\begin{array}{l}\text { 6.1E-04 } \\
(6.287)\end{array}$ & $\begin{array}{l}\text { 4.2E-04 } \\
(4.350)\end{array}$ & $\begin{array}{l}2.9 \mathrm{E}-04 \\
(2.890)\end{array}$ & $\begin{array}{l}2.4 \mathrm{E}-04 \\
(2.255)\end{array}$ & $\begin{array}{l}7.6 \mathrm{E}-05 \\
(0.587)\end{array}$ & $\begin{array}{l}-1.6 \mathrm{E}-04 \\
(-0.782)\end{array}$ & $\begin{array}{l}\text { 8.6E-04 } \\
(5.628)\end{array}$ \\
\hline$I \operatorname{Vol}(-1)$ & $\begin{array}{l}-0.1932 \\
(-29.783)\end{array}$ & $\begin{array}{l}-0.1305 \\
(-28.322)\end{array}$ & $\begin{array}{l}-0.0848 \\
(-21.833)\end{array}$ & $\begin{array}{l}-0.0445 \\
(-12.529)\end{array}$ & $\begin{array}{l}-0.0108 \\
(-3.203)\end{array}$ & $\begin{array}{l}0.0179 \\
(5.083)\end{array}$ & $\begin{array}{l}0.0586 \\
(14.032)\end{array}$ & $\begin{array}{l}0.1190 \\
(21.991)\end{array}$ & $\begin{array}{l}0.1955 \\
(27.152)\end{array}$ & $\begin{array}{l}-0.0053 \\
(-1.143)\end{array}$ \\
\hline$\gamma_{2}{ }^{*}$ & $\begin{array}{l}-0.3526 \\
(-20.767)\end{array}$ & $\begin{array}{l}-0.2099 \\
(-22.864)\end{array}$ & $\begin{array}{l}-0.1288 \\
(-19.913)\end{array}$ & $\begin{array}{l}-0.0655 \\
(-12.242)\end{array}$ & $\begin{array}{l}-0.0161 \\
(-3.155)\end{array}$ & $\begin{array}{l}0.0258 \\
(5.085)\end{array}$ & $\begin{array}{l}0.0851 \\
(13.486)\end{array}$ & $\begin{array}{l}0.1785 \\
(16.566)\end{array}$ & $\begin{array}{l}0.3112 \\
(17.894)\end{array}$ & $\begin{array}{l}-0.0121 \\
(-1.435)\end{array}$ \\
\hline $\mathrm{d}(\mathscr{R}(-1))$ & $\begin{array}{l}-0.1912 \\
(-17.763)\end{array}$ & $\begin{array}{l}-0.1746 \\
(-20.829)\end{array}$ & $\begin{array}{l}-0.1618 \\
(-20.337)\end{array}$ & $\begin{array}{l}-0.1576 \\
(-20.968)\end{array}$ & $\begin{array}{l}-0.1520 \\
(-20.662)\end{array}$ & $\begin{array}{l}-0.1437 \\
(-19.594)\end{array}$ & $\begin{array}{l}-0.1433 \\
(-18.336)\end{array}$ & $\begin{array}{l}-0.1469 \\
(-16.025)\end{array}$ & $\begin{array}{l}-0.1523 \\
(-12.732)\end{array}$ & $\begin{array}{l}-0.1891 \\
(-20.138)\end{array}$ \\
\hline $\mathrm{d}(\operatorname{lnbm})$ & $\begin{array}{l}5.7 E-04 \\
(5.702)\end{array}$ & $\begin{array}{l}5.0 E-04 \\
(6.493)\end{array}$ & $\begin{array}{l}4.1 \mathrm{E}-04 \\
(6.901)\end{array}$ & $\begin{array}{l}\text { 3.9E-04 } \\
(7.415)\end{array}$ & $\begin{array}{l}3.7 \mathrm{E}-04 \\
(6.995)\end{array}$ & $\begin{array}{l}\text { 3.1E-04 } \\
(5.831)\end{array}$ & $\begin{array}{l}3.4 \mathrm{E}-04 \\
(6.228)\end{array}$ & $\begin{array}{l}3.4 \mathrm{E}-04 \\
(4.825)\end{array}$ & $\begin{array}{l}3.9 \mathrm{E}-04 \\
(4.963)\end{array}$ & $\begin{array}{l}6.6 \mathrm{E}-04 \\
(9.584)\end{array}$ \\
\hline $\mathrm{d}(\ln b m(-1))$ & $\begin{array}{l}-4.1 \mathrm{E}-05 \\
(-0.416)\end{array}$ & $\begin{array}{l}-2.9 \mathrm{E}-05 \\
(-0.452)\end{array}$ & $\begin{array}{l}-8.3 E-05 \\
(-1.525)\end{array}$ & $\begin{array}{l}-9.6 \mathrm{E}-05 \\
(-1.800)\end{array}$ & $\begin{array}{l}-5.0 \mathrm{E}-05 \\
(-1.001)\end{array}$ & $\begin{array}{l}-2.1 \mathrm{E}-05 \\
(-0.417)\end{array}$ & $\begin{array}{l}-1.9 \mathrm{E}-05 \\
(-0.319)\end{array}$ & $\begin{array}{l}-2.8 \mathrm{E}-06 \\
(-0.041)\end{array}$ & $\begin{array}{l}1.4 \mathrm{E}-04 \\
(1.609)\end{array}$ & $\begin{array}{l}6.5 \mathrm{E}-05 \\
(1.038)\end{array}$ \\
\hline $\mathrm{d}(I V o l)$ & $\begin{array}{l}-0.1553 \\
(-23.811)\end{array}$ & $\begin{array}{l}-0.1068 \\
(-22.921)\end{array}$ & $\begin{array}{l}-0.0691 \\
(-16.520)\end{array}$ & $\begin{array}{l}-0.0396 \\
(-10.134)\end{array}$ & $\begin{array}{l}-0.0153 \\
(-4.201)\end{array}$ & $\begin{array}{l}0.0106 \\
(2.905)\end{array}$ & $\begin{array}{l}0.0422 \\
(9.525)\end{array}$ & $\begin{array}{l}0.0911 \\
(16.602)\end{array}$ & $\begin{array}{l}0.1561 \\
(22.379)\end{array}$ & $\begin{array}{l}-0.0033 \\
(-0.752)\end{array}$ \\
\hline $\mathrm{d}(\operatorname{IVol}(-1))$ & $\begin{array}{l}0.0235 \\
(4.585)\end{array}$ & $\begin{array}{l}0.0135 \\
(3.903)\end{array}$ & $\begin{array}{l}0.0109 \\
(3.957)\end{array}$ & $\begin{array}{l}0.0028 \\
(1.001)\end{array}$ & $\begin{array}{l}-0.0022 \\
(-0.838)\end{array}$ & $\begin{array}{l}-0.0025 \\
(-0.972)\end{array}$ & $\begin{array}{l}-0.0063 \\
(-2.119)\end{array}$ & $\begin{array}{l}-0.0117 \\
(-3.251)\end{array}$ & $\begin{array}{l}-0.0167 \\
(-3.296)\end{array}$ & $\begin{array}{l}0.00393 \\
1.20122\end{array}$ \\
\hline $\mathrm{R}^{2}$ & 0.3504 & 0.3174 & 0.2991 & 0.2874 & 0.2821 & 0.2838 & 0.2921 & 0.3119 & 0.3564 & 0.4451 \\
\hline $\operatorname{Adj}-R^{2}$ & 0.3242 & 0.2898 & 0.2708 & 0.2587 & 0.2531 & 0.2549 & 0.2635 & 0.2841 & 0.3304 & 0.4227 \\
\hline
\end{tabular}

The coefficient $\alpha$ representing the speed of restoration to equilibrium by short-run adjustments in $\mathscr{R}$ is negative and significant at all quantiles, and implies that the error-correction mechanism is at play throughout the conditional distribution of returns. However, the speed of adjustment in the recovery to equilibrium by the short-run adjustments in $\mathcal{R}$ is slower at the lower quantiles compared to the upper quantiles. This means that the underperforming stocks take longer to reach 
the equilibrium state after a displacement. The long-run implied coefficients values $\gamma_{k}^{*}, \mathrm{k}=0,1,2$, in Table 7 mimic the long-run relationship pattern observed in Table 6 part (b) for intercept, $\ln b m$ and $I V o l$, respectively.

The coefficient of $d(\operatorname{lnbm})$ is positive and significant at all quantiles, and implies that changes in $\operatorname{lnbm}$ ratios impact the short-run adjustments in returns. We observe that the coefficient of $d(I V o l)$ is also significant at all quantiles, but negative (positive) at the lower (upper) quantiles. This pattern allows us to draw two inferences. (i) The changes in IVol affects adversely the shortrun returns of the low performing stocks, but investments in high performing stocks benefit from such changes, and could be interpreted as the short-run momentum effect at play as observed in past studies (e.g., Jagedeesh and Titman 1993). (ii) The increasing trend in marginal effect of $d(\mathrm{IVol})$ on changes in returns suggests that the idiosyncratic risk-return relationship in the levels of the variables (i.e., the long-run relationship) is quadratic. This second inference confirms the pattern observed in Table 6 part (a) and agrees with the Nath and Brooks (2015) finding that the relationship in the levels of expected excess returns and the lagged $I \mathrm{Vol}$ is parabolic ${ }^{12}$. A significant impact of $d(\operatorname{IVol}(-1))$ is also observed at the extreme quantiles of the short-run returns, which supports the presence of persistence in $d(I V o l)$ and, therefore, the persistence in $I V o l$. While the impact of $d(I V o l)$ on $d(\mathscr{R})$ is negative (positive) at the lower (upper) quantiles, the effect $d(\operatorname{IVol}(-1))$ is positive (negative) at lower (upper) quantiles. These reversing signs of the effects of $d(I \mathrm{Vol})$ and $d(\operatorname{IVol}(-1))$ at the same quantile level for a number of extreme quantiles of the distribution of $d(\mathscr{R})$ provide an evidence that the reversion in short-run returns is due to the persistence in IVol. Thus, the short-run dynamics of expected returns is linked to the errorcorrection term, the changes in $\mathrm{IVol}$ and its first lag and changes in $\mathrm{lnbm}$.

Our panel ECM also shows the coefficients of $d(\mathscr{R}(-1))$ as negative and significant at all quantiles, suggesting the existence of a pervasive return-reversal process that spans the entire distribution of short-run adjustments in $\mathscr{R}$ in the Australian stock market. Thus, using the panel ECM and the quantile regression, we are able to establish: (i) the existence of an underlying longrun equilibrium relationship between the returns and the time series of IVol and lnbm; (ii) while the short-run responses of returns to changes in $\operatorname{lnbm}$ are positive, their reaction to persistence in changes in $\mathrm{IVol}$ and, therefore, in IVol cause the reversal process; the system keeps correcting itself to maintain an equilibrium. These patterns could be interpreted as the effect of risk-adverse investors' efforts to adjust their investment moves to take advantage of value-growth opportunities and reduce exposure to idiosyncratic risk.

\subsection{Idiosyncratic risk-return relationship and panel Error Correction Models in size-sorted portfolios}

It is widely documented in the finance literature that firms with smaller market capitalization yield higher returns than larger market capitalization firms (e.g., Banz, 1981; Beedles et al., 1988; Fama and French, 1992; Malkiel and Xu, 1997; O'Brien et al., 2012). Angelidis and Tessaromatis (2008) assert that it is the volatility of small capitalization stocks that matters for asset pricing, and that idiosyncratic volatility of small stocks predicts the small capitalization premium component of the market returns. We observe from the scatter plot of idiosyncratic risk against lnsize in Figure 1 that the larger stocks possess the least amount of idiosyncratic volatility, and agrees with the findings in the literature. Figure 1 also suggests that the relationship is not linear. Thus, it is of interest to explore the impact of size on the return-reversal process and the existence of an equilibrium state resulting from a cointegrated relationship. We expect the idiosyncratic riskreturn relationship in portfolios formed on size to reveal some degree of variation in form and strength.

12 Nath and Brooks (2015) show that the parabolic relation between idiosyncratic risk and stock returns is quantile dependent; it is U-shaped (inverted U-shaped) at the lower (upper) quantiles, flipping curvature around the median. The changing curvature may be due to the risk-aversion of traders trying to balance the risk and the returns. 
Size-sorted portfolios are formed using 20-day blocks. At the end of each 20-day period, stocks are sorted on lnsize and divided into three equal size groups to form portfolios of small, medium and large stocks. Once again we have a panel data structure, where each panel consists of average excess returns realized from holding a stock for a 20-day period, lnsize, $\operatorname{lnbm}$, beta-risk estimates, coefficients of Fama-French factors SMB and HML, and idiosyncratic risk for each stock. This allows evaluation of all models considered earlier within the size-sorted portfolios, however we report only the reduced variables models. Table 8 (a) reports summary statistics on Insize of stocks in three size-sorted portfolios. It is clear that the lnsize characteristics of stocks in the three portfolios are quite different. The mean and median Insize for the three portfolios are not the same; the variation in the portfolio of medium size stocks is smaller than the other two. The distribution of Insize in the small and medium size stocks portfolios is very close to being symmetric but is positively skewed in large stocks portfolio. The lnsize distribution in small stocks portfolio is more peaked compared to the other two.

The long-run relationships in size-sorted portfolios are first evaluated using the OLS and the quantile regression methods for benchmarking. Table 8 (b) lists the estimated coefficients and the associated test statistic values from fitting the reduced variables models. The OLS estimate of the intercept of the long-run relationship is positive and significant only in the portfolio of small stocks; it is virtually zero in the other two. The quantile regression estimates of intercept are negative (positive) at the lower (upper) quantiles in each portfolio, but the estimates are significant mostly in the small stocks portfolio.

Table 8

Long-run idiosyncratic risk-return relationship in size-sorted portfolios

(a) Summary statistics of variable lnsize in size-sorted portfolios

\begin{tabular}{lccccccc}
\hline \hline & Mean & Median & Mode & StDev & Kurtosis & Skewness & N \\
\hline Small & 3.94142 & 3.96765 & 3.05447 & 1.12219 & 1.34617 & 0.09623 & 8143 \\
Medium & 6.18900 & 6.18948 & 5.94201 & 0.75735 & 0.41665 & -0.09908 & 8143 \\
Large & 8.48466 & 8.37071 & 7.02252 & 1.11750 & 0.39748 & 0.45473 & 8143 \\
\hline \hline
\end{tabular}

(b) The quantile regression and OLS estimation of idiosyncratic risk-return relationship in size-sorted portfolios using reduced number of explanatory variables. The response variable is $\mathcal{R}$. The reported values are obtained using the Fama-MacBeth (1973) pooling method; the associated $t$-statistic values are in parentheses. Significant coefficient estimates are displayed in bold.

Small stocks

\begin{tabular}{|c|c|c|c|c|c|c|c|c|c|c|}
\hline & & & & & Quantile & & & & & \\
\hline Variable & 0.1 & 0.2 & 0.3 & 0.4 & 0.5 & 0.6 & 0.7 & 0.8 & 0.9 & OLS \\
\hline intercept & $\begin{array}{l}-0.0023 \\
(-3.923)\end{array}$ & $\begin{array}{c}-9.0 \mathrm{E}-04 \\
(-2.005)\end{array}$ & $\begin{array}{r}-7.6 \mathrm{E}-05 \\
(-0.213)\end{array}$ & $\begin{array}{c}5.2 \mathrm{E}-04 \\
(1.475)\end{array}$ & $\begin{array}{l}0.0012 \\
(3.539)\end{array}$ & $\begin{array}{l}0.0017 \\
(4.781)\end{array}$ & $\begin{array}{l}0.0023 \\
(5.561)\end{array}$ & $\begin{array}{l}0.0031 \\
(6.094)\end{array}$ & $\begin{array}{r}0.0045 \\
(6.444)\end{array}$ & $\begin{array}{c}0.0011 \\
(2.713)\end{array}$ \\
\hline $\operatorname{lnbm}$ & $\begin{array}{l}0.0010 \\
(4.516)\end{array}$ & $\begin{array}{c}7.0 \mathrm{E}-04 \\
(4.445)\end{array}$ & $\begin{array}{c}6.3 E-04 \\
(4.421)\end{array}$ & $\begin{array}{c}5.7 E-04 \\
(4.173)\end{array}$ & $\begin{array}{c}6.9 E-04 \\
(4.953)\end{array}$ & $\begin{array}{c}6.8 E-04 \\
(4.756)\end{array}$ & $\begin{array}{c}8.0 E-04 \\
(4.926)\end{array}$ & $\begin{array}{l}0.0010 \\
(5.335)\end{array}$ & $\begin{array}{c}\text { 9.0E-04 } \\
(3.071)\end{array}$ & $\begin{array}{l}0.0010 \\
(6.663)\end{array}$ \\
\hline IVol & $\begin{array}{l}-0.2167 \\
(-7.972)\end{array}$ & $\begin{array}{l}-0.1740 \\
(-7.988)\end{array}$ & $\begin{array}{l}-0.1328 \\
(-7.733)\end{array}$ & $\begin{array}{l}-0.0957 \\
(-5.470)\end{array}$ & $\begin{array}{l}-0.0581 \\
(-3.406)\end{array}$ & $\begin{array}{l}-0.0235 \\
(-1.223)\end{array}$ & $\begin{array}{l}0.0249 \\
(1.127)\end{array}$ & $\begin{array}{l}0.0921 \\
(3.543)\end{array}$ & $\begin{array}{l}0.1592 \\
(3.963)\end{array}$ & $\begin{array}{l}-0.0359 \\
(-1.751)\end{array}$ \\
\hline $\mathrm{IVol}^{2}$ & $\begin{array}{l}1.4051 \\
(4.454)\end{array}$ & $\begin{array}{l}1.2460 \\
(4.706)\end{array}$ & $\begin{array}{l}0.9235 \\
(4.310)\end{array}$ & $\begin{array}{l}0.6630 \\
(3.162)\end{array}$ & $\begin{array}{l}0.3949 \\
(1.995)\end{array}$ & $\begin{array}{l}0.2700 \\
(1.155)\end{array}$ & $\begin{array}{l}0.0948 \\
(0.351)\end{array}$ & $\begin{array}{l}-0.3780 \\
(-1.171)\end{array}$ & $\begin{array}{l}-0.3035 \\
(-0.563)\end{array}$ & $\begin{array}{l}0.4162 \\
(1.647)\end{array}$ \\
\hline $\mathrm{R}^{2}$ & 0.1100 & 0.0771 & 0.0616 & 0.0522 & 0.0466 & 0.0465 & 0.0526 & 0.0728 & 0.1144 & 0.0799 \\
\hline Adj-R ${ }^{2}$ & 0.0690 & 0.0345 & 0.0183 & 0.0085 & 0.0026 & 0.0025 & 0.0088 & 0.0300 & 0.0735 & 0.0374 \\
\hline
\end{tabular}


Medium stocks

\begin{tabular}{|c|c|c|c|c|c|c|c|c|c|c|}
\hline intercept & $\begin{array}{l}-0.0022 \\
(-2.861)\end{array}$ & $\begin{array}{l}-0.0013 \\
(-2.825)\end{array}$ & $\begin{array}{c}-6.0 \mathrm{E}-04 \\
(-1.743)\end{array}$ & $\begin{array}{c}-6.2 \mathrm{E}-04 \\
(-1.923)\end{array}$ & $\begin{array}{c}-1.8 \mathrm{E}-04 \\
(-0.563)\end{array}$ & $\begin{array}{c}2.9 \mathrm{E}-04 \\
(0.870)\end{array}$ & $\begin{array}{c}6.2 \mathrm{E}-04 \\
(1.588)\end{array}$ & $\begin{array}{l}0.0011 \\
(2.531)\end{array}$ & $\begin{array}{c}0.0011 \\
(1.948)\end{array}$ & $\begin{array}{c}-1.1 \mathrm{E}-04 \\
(-0.263)\end{array}$ \\
\hline $\operatorname{lnbm}$ & $\begin{array}{c}6.8 E-04 \\
(3.255)\end{array}$ & $\begin{array}{c}\text { 4.9E-04 } \\
(3.164)\end{array}$ & $\begin{array}{c}4.8 E-04 \\
(3.942)\end{array}$ & $\begin{array}{c}4.2 \mathrm{E}-04 \\
(4.354)\end{array}$ & $\begin{array}{c}3.5 E-04 \\
(3.814)\end{array}$ & $\begin{array}{c}2.7 \mathrm{E}-04 \\
(2.816)\end{array}$ & $\begin{array}{c}3.1 \mathrm{E}-04 \\
(3.121)\end{array}$ & $\begin{array}{l}1.5 \mathrm{E}-04 \\
(1.506)\end{array}$ & $\begin{array}{c}8.3 \mathrm{E}-05 \\
(0.605)\end{array}$ & $\begin{array}{c}4.2 E-04 \\
(4.237)\end{array}$ \\
\hline IVol & $\begin{array}{l}-0.1792 \\
(-3.691)\end{array}$ & $\begin{array}{l}-0.0862 \\
(-2.281)\end{array}$ & $\begin{array}{l}-0.0426 \\
(-1.413)\end{array}$ & $\begin{array}{l}0.0268 \\
(0.982)\end{array}$ & $\begin{array}{l}0.0466 \\
(1.783)\end{array}$ & $\begin{array}{l}0.0626 \\
(2.341)\end{array}$ & $\begin{array}{l}0.1006 \\
(3.432)\end{array}$ & $\begin{array}{l}0.1404 \\
(4.003)\end{array}$ & $\begin{array}{l}0.2995 \\
(6.624)\end{array}$ & $\begin{array}{l}0.0306 \\
(1.023)\end{array}$ \\
\hline $\mathrm{IVol}^{2}$ & $\begin{array}{l}0.8024 \\
(0.691)\end{array}$ & $\begin{array}{l}-0.3670 \\
(-0.402)\end{array}$ & $\begin{array}{l}-1.0305 \\
(-1.315)\end{array}$ & $\begin{array}{l}-1.7493 \\
(-2.431)\end{array}$ & $\begin{array}{l}-1.3039 \\
(-1.907)\end{array}$ & $\begin{array}{l}-1.0607 \\
(-1.567)\end{array}$ & $\begin{array}{l}-1.0546 \\
(-1.564)\end{array}$ & $\begin{array}{l}-0.9525 \\
(-1.102)\end{array}$ & $\begin{array}{l}-3.4396 \\
(-3.122)\end{array}$ & $\begin{array}{l}-0.9235 \\
(-1.476)\end{array}$ \\
\hline $\mathrm{R}^{2}$ & 0.1279 & 0.0886 & 0.0673 & 0.0537 & 0.0485 & 0.0524 & 0.0607 & 0.0767 & 0.1153 & 0.0930 \\
\hline $\operatorname{Adj}-R^{2}$ & 0.0876 & 0.0465 & 0.0243 & 0.0101 & 0.0046 & 0.0087 & 0.0173 & 0.0341 & 0.0745 & 0.0512 \\
\hline \multicolumn{11}{|c|}{ Large stocks } \\
\hline intercept & $\begin{array}{c}-8.0 \mathrm{E}-04 \\
(-1.739)\end{array}$ & $\begin{array}{c}-4.6 \mathrm{E}-04 \\
(-1.456)\end{array}$ & $\begin{array}{c}-1.7 \mathrm{E}-04 \\
(-0.615)\end{array}$ & $\begin{array}{c}8.8 \mathrm{E}-05 \\
(0.299)\end{array}$ & $\begin{array}{c}1.7 \mathrm{E}-04 \\
(0.613)\end{array}$ & $\begin{array}{c}3.5 \mathrm{E}-04 \\
(1.490)\end{array}$ & $\begin{array}{c}6.2 \mathrm{E}-04 \\
(2.015)\end{array}$ & $\begin{array}{l}0.0010 \\
(2.718)\end{array}$ & $\begin{array}{l}0.0012 \\
(3.061)\end{array}$ & $\begin{array}{c}8.9 \mathrm{E}-05 \\
(0.325)\end{array}$ \\
\hline $\operatorname{lnbm}$ & $\begin{array}{c}5.1 E-04 \\
(3.695)\end{array}$ & $\begin{array}{c}2.5 \mathrm{E}-04 \\
(2.025)\end{array}$ & $\begin{array}{c}1.8 \mathrm{E}-04 \\
(1.707)\end{array}$ & $\begin{array}{c}1.5 \mathrm{E}-04 \\
(1.508)\end{array}$ & $\begin{array}{c}2.0 \mathrm{E}-05 \\
(0.231)\end{array}$ & $\begin{array}{c}1.4 \mathrm{E}-05 \\
(0.172)\end{array}$ & $\begin{array}{c}-4.7 \mathrm{E}-05 \\
(-0.547)\end{array}$ & $\begin{array}{c}-1.2 \mathrm{E}-04 \\
(-1.330)\end{array}$ & $\begin{array}{c}-1.6 \mathrm{E}-04 \\
(-1.457)\end{array}$ & $\begin{array}{l}1.1 \mathrm{E}-04 \\
(1.326)\end{array}$ \\
\hline IVol & $\begin{array}{l}-0.2305 \\
(-4.386)\end{array}$ & $\begin{array}{l}-0.1613 \\
(-4.295)\end{array}$ & $\begin{array}{l}-0.1030 \\
(-2.948)\end{array}$ & $\begin{array}{l}-0.0638 \\
(-1.736)\end{array}$ & $\begin{array}{l}-0.0092 \\
(-0.255)\end{array}$ & $\begin{array}{l}0.0287 \\
(0.889)\end{array}$ & $\begin{array}{l}0.0666 \\
(1.632)\end{array}$ & $\begin{array}{c}0.1110 \\
(2.344)\end{array}$ & $\begin{array}{l}0.2260 \\
(4.429)\end{array}$ & $\begin{array}{l}0.0047 \\
(0.137)\end{array}$ \\
\hline $\mathrm{IVol}^{2}$ & $\begin{array}{l}3.2552 \\
(1.958)\end{array}$ & $\begin{array}{l}2.1043 \\
(1.779)\end{array}$ & $\begin{array}{l}1.0309 \\
(0.920)\end{array}$ & $\begin{array}{l}0.7803 \\
(0.637)\end{array}$ & $\begin{array}{l}-0.2528 \\
(-0.201)\end{array}$ & $\begin{array}{l}-0.3582 \\
(-0.289)\end{array}$ & $\begin{array}{l}-0.6227 \\
(-0.435)\end{array}$ & $\begin{array}{l}-1.0528 \\
(-0.653)\end{array}$ & $\begin{array}{l}-3.5563 \\
(-2.119)\end{array}$ & $\begin{array}{l}-0.5057 \\
(-0.428)\end{array}$ \\
\hline $\mathrm{R}^{2}$ & 0.1152 & 0.0843 & 0.0687 & 0.0616 & 0.0583 & 0.0612 & 0.0669 & 0.0805 & 0.1181 & 0.0966 \\
\hline $\operatorname{Adj}-R^{2}$ & 0.0743 & 0.0421 & 0.0257 & 0.0183 & 0.0148 & 0.0179 & 0.0238 & 0.0381 & 0.0774 & 0.0549 \\
\hline
\end{tabular}

The positive marginal effect of $\operatorname{lnbm}$ on returns is most prominent in portfolios of small and medium size stocks. The OLS estimate of $\operatorname{lnbm}$ effect, although positive in all portfolios, is significant only in the portfolios of small and medium size stocks. The quantile regression estimates show positive and significant effect of $l \mathrm{nbm}$ throughout the distribution of returns in small stocks portfolio, up to quantile 0.7 for the medium size stocks, and at quantiles 0.1 and 0.2 of the large stocks. Thus, it follows that only the small capitalization stocks benefit from the value-growth opportunities.

The OLS estimate of the coefficient of $\mathrm{IVol}$, is negative (positive) in small (medium and larger) stocks portfolio(s) but not significant. The quantile regression slope coefficients of $I V o l$ in all size portfolios, representing the linear relationship between $I V o l$ and $\mathscr{R}$, are negative (positive) at the lower (upper) quantiles - a pattern which has been observed in all reported models thus far. The coefficients of this long-run relationship are significant only at the extreme quantiles in all portfolios, but the significant effect is most prominent among the smaller stocks.

Given that we observe a strong nonlinear relation between average lnsize and average IVol (Figure 1), it is no surprise that the quadratic effect of $I V o l$ on $\mathcal{R}$ is dominant only among the small stocks. The OLS estimates of the coefficients of $I \mathrm{Vol}^{2}$ are not significant in any of the portfolios, but its effect is positive (negative) in small (medium and large) stocks' portfolio(s). The quantile regression based coefficients of $\mathrm{IVol}^{2}$ are positive (negative) at lower (upper) quantiles, but are significant only at the lower quantiles (0.1 to 0.5$)$ in the small stocks portfolio and at the $90^{\text {th }}$ quantile in the portfolio of medium and large stocks. Viewing pairs of significant quantile regression estimates of coefficients of $\mathrm{IVol}$ and $\mathrm{IVol}^{2}$ in the three size-sorted portfolios, and following discussions in Nath and Brooks (2015), one can say that a U-shaped quadratic risk-return relationship is prevalent in the left half of the returns distribution in the portfolio of 
small stocks, but an Inverted-U-shaped distribution in the returns of the medium and large stocks at the $90^{\text {th }}$ quantile. It follows then that while investors are comfortable with taking on higher idiosyncratic risk with some underperforming small stocks, they are more cautious when dealing with large capitalization stocks. This conclusion should not be a surprise given that Figure 1 shows a weak and almost flat relationship between idiosyncratic volatility and large capitalization stocks. However, such conclusions cannot be drawn on the basis of pattern observed in the OLS estimates.

\section{Table 9}

Ordinary least squares estimation of Panel Error-Correction Models in size-sorted portfolios: This table reports OLS fitting of panel ECM in size-sorted portfolios using explanatory variables $l \mathrm{lnbm}$ and $\mathrm{IVol}$, an equivalent of ECM 1 in Table 5 part (b). The response variable is $d(\mathscr{R})$. The first column displays the explanatory variables employed in the model, and the implied parameters $\gamma_{k}^{*}, \mathrm{k}=0,1,2$, (denoting the intercept and the coefficients of lnbm, IVol and $\mathrm{IVol}^{2}$, respectively) obtained using the relation $\lambda^{\prime}=-\alpha \gamma$ '. Notation $Z(-1)$ stands for 'lag one' value of variable $Z$, and $d(Z)$, the first differences. The reported values are the Fama-MacBeth (1973) pooled estimates and the associated $t$-statistic values are in parentheses. Significant coefficient estimates of important variables are displayed in bold.

\begin{tabular}{|c|c|c|c|c|c|c|}
\hline \multirow[b]{2}{*}{ Intercept } & \multicolumn{2}{|c|}{ Small } & \multicolumn{2}{|c|}{ Medium } & \multicolumn{2}{|c|}{ Large } \\
\hline & $6.1 \mathrm{E}-04$ & $(3.237)$ & $1.6 \mathrm{E}-04$ & $(0.709)$ & 4.6E-04 & $(2.300)$ \\
\hline$\gamma_{0}^{*}$ & 0.0018 & (1.905) & -0.0051 & $(-1.119)$ & 0.0015 & (2.627) \\
\hline $\mathcal{R}(-1)$ & -0.5764 & $(-26.979)$ & -0.6425 & $(-31.102)$ & -0.6389 & $(-33.418)$ \\
\hline $\ln b m(-1)$ & $6.8 \mathrm{E}-04$ & (4.193) & $3.0 \mathrm{E}-04$ & (1.997) & 4.7E-04 & $(2.885)$ \\
\hline$\gamma_{1}^{*}$ & 0.0018 & (2.399) & -0.0010 & $(-1.324)$ & $5.0 \mathrm{E}-04$ & (1.303) \\
\hline $\operatorname{IVol}(-1)$ & -0.0127 & $(-1.571)$ & 0.0014 & $(0.156)$ & -0.0057 & $(-0.693)$ \\
\hline$\gamma_{2}^{*}$ & -0.0436 & $(-0.892)$ & -0.1099 & $(-0.852)$ & -0.0582 & $(-1.678)$ \\
\hline $\mathrm{d}(\mathscr{R}(-1))$ & -0.2199 & $(-13.035)$ & -0.1744 & $(-10.921)$ & -0.1833 & $(-11.059)$ \\
\hline $\mathrm{d}(\operatorname{lnbm})$ & 7.0E-04 & (5.034) & 6.0E-04 & (5.036) & $5.7 \mathrm{E}-04$ & (5.381) \\
\hline $\mathrm{d}(\ln b m(-1))$ & 8.0E-05 & $(0.734)$ & 7.3E-05 & $(0.725)$ & $-7.5 \mathrm{E}-05$ & $(-0.681)$ \\
\hline $\mathrm{d}(I V o l)$ & -0.0099 & $(-1.323)$ & -0.0040 & $(-0.496)$ & $-2.8 \mathrm{E}-04$ & $(-0.037)$ \\
\hline $\mathrm{d}(\operatorname{IVol}(-1))$ & 0.0054 & (1.038) & 0.0053 & $(0.857)$ & -0.0014 & $(-0.257)$ \\
\hline $\mathrm{R}^{2}$ & 0.4903 & & 0.5132 & & 0.5114 & \\
\hline Adj- $R^{2}$ & 0.4223 & & 0.4483 & & 0.4462 & \\
\hline
\end{tabular}

Table 9 reports the OLS estimation of panel ECM 1 in size-sorted portfolios. The comments related to the panel error-correction models that are made at the end of Section 4.1.1 can be reiterated for the size-sorted portfolios with a few exceptions. The implied long-run positive dependence between $R$ and $\operatorname{lnbm}$ at the mean level is significant only among the smaller stocks. It follows once again that only the small capitalization stocks benefit from the value-growth opportunities. The coefficients of $\mathscr{R}(-1)$ are negative and significant in each size portfolio that suggests that error-correction mechanism is at play and that the panel cointegration exists within the size-sorted portfolios. However, $\alpha$, the speed of convergence to equilibrium by the response of $\mathscr{R}$ is faster among the medium and large stocks compared to small stocks. This means that after a shock, the expected returns from medium and large stocks restore the equilibrium state faster than the small stocks. These findings are in agreement with the ones documented by Chordia et al. (2005) and Lu-Andrews and Glascock (2014), which are based on very different perspectives and methodologies. Further analysis suggests that $\alpha$ for the small stocks is significantly lower than the $\alpha \mathrm{s}$ for the medium and large stocks. 


\section{CONCLUDING REMARKS}

The US based study of CGW (1993) describes the return-reversal process observed to generate large abnormal profits from following some stock market trading strategies via the rational equilibrium paradigm. CGW explain that the phenomenon occurs due to the short-run liquidity imbalance in the market. The shifts in demand by liquidity traders cause price deviations from the fundamentals and offer profit opportunities to risk-averse market makers. The absorption of liquidity demand by market makers causes the prices to revert. Thus, the lack of liquidity moves stock prices away from the fundamentals and the supply of liquidity induces return reversals.

Employing the Australian data, this paper presents a new explanation of the return-reversal process at the firm level and the presence of an equilibrium state via empirical evidence based on econometric methodology of panel error-correction model (ECM). The model exploits the persistence in explanatory variables and builds on their cointegration with the returns series. It allows for the existence of an underlying long-run relationship between the returns and the explanatory variables, incorporates short-run adjustments in variables to correct persistence imbalance due to the nonstationary predictors within the panel data structure. As the panel ECM involves all stationary variables, it can be estimated using any of the classical estimation methods. This paper makes use of the ordinary least squares estimation for bench marking and the quantile regression estimation for deeper understanding of the relationship patterns.

We apply the ADF and the KPSS tests for assessing the time series of idiosyncratic (IVol) risk, $\operatorname{lnbm}$ (log book-to-market), Insize (log of market capitalization) and stock excess returns for unit roots, and the error-correction panel cointegration tests of Westerlund (2007) for establishing a panel cointegration between the realized future excess returns series and variables $I V o l$ and $l n b m$. The estimated panel error-correction models (Table 5 (b), ECM 1 and ECM 2; Table 7) reveal the tendency of long-run returns to restore equilibrium via the error-correction mechanism, and that the short-run returns dynamics is linked to one-period lagged changes in returns, changes in lnbm, changes in $\mathrm{IVol}$ and the error-correction term. The existence of an underlying long-run equilibrium relationship, although between returns and variables $\mathrm{IVol}$ and $\mathrm{lnbm}$, support the rational equilibrium paradigm of CGW (1993). The patterns suggests that while the short-run responses of returns to changes in $\ln b m$ are positive, their reaction to persistence in $\mathrm{IVol}$ causes the reversal process - a pattern that could be interpreted as the effect of risk-averse investors' efforts to adjust their investment moves to take advantage of value-growth opportunities and to reduce exposure to idiosyncratic risk. The dominant role displayed by $\mathrm{IVol}$ risk in our models is consistent with the strong connection observed between price momentum and the idiosyncratic volatility in Arena et al. (2008) study.

A significant negative (positive) impact of changes in $\mathrm{IVol}$ risk at the lower (upper) quantiles of the conditional distribution of short-run returns (Table 7) can be inferred in two ways. (i) The changes in $\mathrm{IVol}$ risk adversely affects the short-run returns of the low performing stocks but investments in high performing stocks benefit from such changes, and could be interpreted as the short-run momentum effect observed in past studies (e.g., Jagedeesh and Titman 1993). (ii) The increasing trend in the coefficients implies a quadratic relationship in the levels of the two series, and could mean that investors' investment strategies change with the level of exposure to IVol risk and the stakes involved (see, e.g., Nath and Brooks 2015). The significant marginal effects of changes in $\mathrm{IVol}$ and its one period lagged values on short-run returns at many quantiles support the persistence in $\mathrm{IVol}$ risk, and their reversing signs present an evidence of reversion in short-run returns. Further indication of short-run return-reversals is provided by the negative significant coefficients of one-period lagged changes in returns.

The analysis within the size-sorted portfolios highlights the importance of the role played by the market capitalization of stocks. The quantile regression estimation (Table 8 (b)) reveals that the quadratic form of the long-run idiosyncratic risk-return relationship is mainly confined to small stocks. The returns of small stocks bear the most effect of $I V o l$ risk and $l n b m$, and it is the 
idiosyncratic volatility and value-growth opportunities associated with small stocks that seem to dominate the asset pricing. We also observe (Table 9) that while the reversal in short-run returns is more dominant among the small stocks, the recovery rate to equilibrium by the response of small stocks' returns is slower.

In this study, we have initiated an application of a panel ECM for showing the existence of a short-run return-reversal process and an underlying long-run equilibrium relationship being maintained via a panel cointegration between the time series of returns and variables IVol and $\mathrm{lnbm}$. The concepts of return-reversals and the existence of an underlying equilibrium are pursued in some US based studies that also seek a more sophisticated model for understanding the return regularities observed in stock market trading. While the current study is based on the Australian data, it would be of interest for the future research to weigh up our modelling framework by applying it to other stock markets using different time horizons, different holding periods to realize profits, and using predictors like liquidity and/ or the trading volume.

\section{Acknowledgements}

We thank the Editor-in-Chief Professor Malgorzata Olszak and the anonymous reviewers for providing constructive feedback that helped to clarify and improve this paper.

\section{References}

Ang, A., Hodrick, R., Xing, Y., Zhang, X. (2006) The cross-Section of volatility and future excess returns, Journal of Finance 61, pp. 259-299.

Ang, A., Hodrick, R., Xing, Y., Zhang, X. (2009) High idiosyncratic volatility and low returns: International and further U.S. evidence, Journal of Financial Economics,91, pp. 1-23.

Angelidis, T., Tessaromatis, N. (2008) Idiosyncratic volatility and equity returns: UK evidence, International review of Financial Analysis 17, pp. 539-556.

Arena, M.P., Haggard, K.S., Yan, X. (2008) Price momentum and idiosyncratic volatility, The Financial Review 43, pp. 159-190.

Avramov, D., Chordia, T., Goyal, A. (2006) Liquidity and Autocorrelations in Individual Stock Returns, Journal of Finance 61, pp. 2365-2394.

Banz, R. W. (1981) The relationship between return and market value of common stocks, Journal of Financial Economics 9, pp. 3-18.

Barnes, M., Hughes, A. (2002) A quantile regression analysis of the cross section of stocks market returns, Working paper (http://ssrn.com/absract=458522).

Bassett Jr, G. W., Chen, H. (2001) Portfolio style: Return-based attribution using quantile regression, Empirical Economics 26, pp. 293-305.

Beedles, W. L., Dodd, P., Officer, R. R. (1988) Regularities in Australian Share Returns, Australian Journal of Management 13, pp. 1-29.

Buchinsky, M. (1997) The dynamics of changes in the female wage distribution in the USA: A quantile regression approach, Journal of Applied Econometrics 13, pp. 1-30.

Buchinsky, M. (1998) Recent advances in quantile regression models: A practical guideline for empirical research, Journal of Human Resources 33, pp. 88-126.

Campbell, J. Y., Grossman, S. J., Wang, J. (1993) Trading Volume and Serial Correlation in Stock Returns, The Quarterly Journal of Economics 108, pp. 905-939.

Campbell, J. Y., Lettau, M., Malkiel, B. G., Xu, Y. (2001) Have individual stocks become more volatile? An empirical exploration of idiosyncratic risk, Journal of Finance 56, pp. 1-43.

Chordia, T., Roll, R., Subrahmanyam, A. (2005) Evidence on the speed of convergence to market efficiency, Journal of Financial Economics 76, pp. 271-292.

Connolly, R., Stivers, C. (2003) Momentum and Reversals in Equity-Index Returns During Periods of Abnormal Turnover and Return Dispersion, The Journal of Finance 58, pp. 1521-1555.

De Bondt, W. F. M., Thanler, R. (1985) Does the stock market overreact? Journal of Finance 40, pp. $793-805$.

Drew, M.E., Veeraraghavan, M., Ye, M. (2007) Do momentum strategies work? Australian evidence, Managerial Finance 33, pp.772-787. 
Engle, R., Granger, C. (1987) Co-integration and Error Correction: Representation, Estimation, and Testing, Econometrica 35, pp. 251-276.

Engle, R. F., Manganelli, S. (2004) CAViaR: Conditional Value at Risk by Regression Quantile, Journal of Business, Economics and Statistics 22, pp. 367-381.

Fama, E., MacBeth, J. (1973) Risk, return and equilibrium: Empirical tests, Journal of Political Economy 81, pp. $607-636$.

Fama, E., French, K. (1988) Permanent and temporary components of stock prices, Journal of Political Economy 96 , pp. 247-273.

Fama, E., French, K. (1992) The cross-section of future excess returns, Journal of Finance 47, pp. 427-465.

Fama, E., French, K. (1993) Common risk factors in the returns on stocks and bonds, Journal of Financial Economics 33 , pp. 3-56.

Fu, F. (2009) Idiosyncratic risk and the cross-section of expected stock returns, Journal of Financial Economics 91, pp. 24-37.

Goyal, A., Santa-Clara, P. (2003) Idiosyncratic Risk Matters! Journal of Finance 58, pp. 975-1007.

Greene, W. H. (2012) Econometric Analysis, Pearson Education Limited, Essex, England

Huang, W., Liu, Q., Rhee, S., Zhang, L. (2010) Return Reversals, Idiosyncratic Risk, and Expected Returns, Review of Financial Studies 23, pp. 147-168.

Hur, T. S. (2010) Idiosyncratic volatility and future excess returns in the Australian market. Master of Business Thesis, Auckland University of Technology, New Zealand.

Jiang, G., Xu, D., Yao, T. (2009) The information content of idiosyncratic volatility, Journal of Financial and Quantitative Analysis 44, pp. 1-28.

Jiang, X., Lee, B. S. (2006) On the dynamic relation between returns and idiosyncratic volatility, Financial Management 35, pp. 43-65.

Jegadeesh, N. (1990) Evidence of Predictable Behavior of Security Returns, Journal of Finance 45, pp. 881-898.

Jegadeesh, N., Titman, S. (1993) Returns to Buying Winners and Selling Losers: Implications for Stock market Efficiency, Journal of Finance 48, pp. 65-91.

Koenker, R., Bassett, G. (1978) Regression Quantiles, Econometrica, 46, pp. 33-50.

Koenker, R., Hallock, K. (2001) Quantile Regression, Journal of Economics Perspectives 15, pp. $143-156$.

Kuan, T., Li, C., Liu, C. (2012) Corporate governance and cash holdings: A quantile regression approach, International Review of Economics and Finance 24, pp. 303-314.

Kumar, S., Rao, B. (2012) Error-correction based panel estimates of the demand for money of selected Asian countries with the extreme bound analysis, Economic Modelling 29, pp. 1181-1188.

Lehmann, B. N. (1990) Fads, Martingales, and Market Efficiency, The Quarterly Journal of Economics 105, pp. 1-28.

Lu-Andrews, R., Glascock, J. L. (2014) Liquidity, Price Behavior and Market-related Events, (Unpublished paper), Available at SSRN 1571512.

Levy, H. (1978) Equilibrium in an imperfect market: a constraint on the number of securities in the portfolio, American Economic Review 68, pp. 643-658.

Malkiel, B., Xu, Y. (2004) Idiosyncratic risk and security returns, (unpublished working paper), University of Texas at Dallas.

Markowitz, H., (1959) Portfolio Selection: Efficient Diversification of Investments, New York: Wiley.

Merton, R., (1971) Optimum consumption and portfolio rules in a continuous-time model, Journal of Economic Theory 3, pp. 373-413.

Merton, R., (1973) An intertemporal capital asset pricing model, Econometrica 41, pp. 876-887.

Merton, R. (1987) A simple model of capital market equilibrium with incomplete information, The Journal of Finance 42, pp. 483-510.

Nath, H. B., Brooks, R. D. (2015) Assessing the idiosyncratic risk and stock returns relation in heteroskedasticity corrected predictive models using quantile regression, International Review of Economics and Finance 38, pp. 94-111.

O’ Brien, M. A., Brailsford, T., Gaunt, C. (2012) Size and Book-to-market Factors in Australia. Australian Journal of Management 37, pp. 261-281.

Pedroni, P. (2004) Panel cointegration: asymptotic and finite sample properties of pooled time series tests with an application to the PPP hypothesis, Econometric Theory 3, pp. 579-625.

Ren, Y., Tu, Y., Yi, Y. (2015) Balanced Predictive Regressions, Monash University and Xiamen University Joint Workshop on Economics, Econometrics and Statistics, Dec 2015, Melbourne, Australia.

Rouwenhorst, K.G. (1998) International Momentum Strategies, The Journal of Finance 53, pp. 267-284.

Sims, C.A. (1984) Martingale-like Behavior of Prices and Interest Rates, Discussion Paper No. 205, Center for Economic Research, University of Minnesota.

Westerlund, J. (2007) Testing for Error Correction in Panel Data, Oxford Bulletin of Economics and Statistics 69, pp. 709-748.

Wan, C. (2008) Idiosyncratic volatility, expected windfall, and the cross-section of stock returns, Sighted at (www. acem.sjtu.edu.cn/upload/publish/img/1091231016500.pdf). 